IZA DP No. 1189

Occupational Mobility and Wage Inequality

Gueorgui Kambourov Iourii Manovskii

J une 2004 


\title{
Occupational Mobility and Wage Inequality
}

\author{
Gueorgui Kambourov \\ University of Toronto \\ lourii Manovskii \\ University of Pennsylvania \\ and IZA Bonn
}

Discussion Paper No. 1189

June 2004

\author{
IZA \\ P.O. Box 7240 \\ 53072 Bonn \\ Germany \\ Phone: +49-228-3894-0 \\ Fax: +49-228-3894-180 \\ Email: iza@iza.org
}

Any opinions expressed here are those of the author(s) and not those of the institute. Research disseminated by IZA may include views on policy, but the institute itself takes no institutional policy positions.

The Institute for the Study of Labor (IZA) in Bonn is a local and virtual international research center and a place of communication between science, politics and business. IZA is an independent nonprofit company supported by Deutsche Post World Net. The center is associated with the University of Bonn and offers a stimulating research environment through its research networks, research support, and visitors and doctoral programs. IZA engages in (i) original and internationally competitive research in all fields of labor economics, (ii) development of policy concepts, and (iii) dissemination of research results and concepts to the interested public.

IZA Discussion Papers often represent preliminary work and are circulated to encourage discussion. Citation of such a paper should account for its provisional character. A revised version may be available on the IZA website (www.iza.org) or directly from the author. 


\section{ABSTRACT}

\section{Occupational Mobility and Wage Inequality*}

In this study we argue that wage inequality and occupational mobility are intimately related. We are motivated by our empirical findings that human capital is occupation-specific and that the fraction of workers switching occupations in the United States was as high as $16 \%$ a year in the early 1970 s and had increased to $19 \%$ by the early 1990 s. We develop a general equilibrium model with occupation-specific human capital and heterogeneous experience levels within occupations. We argue that the increase in occupational mobility was due to the increase in the variability of productivity shocks to occupations. The model, calibrated to match the increase in occupational mobility, accounts for over $90 \%$ of the increase in wage inequality over the period. A distinguishing feature of the theory is that it accounts for changes in within-group wage inequality and the increase in the variability of transitory earnings.

JEL Classification: E20, E24, E25, J24, J31, J62

Keywords: occupational mobility, wage inequality, within-group inequality, human capital, sectoral reallocation

Corresponding author:

lourii Manovskii

Department of Economics

University of Pennsylvania

160 McNeil Building

3718 Locust Walk

Philadelphia, PA 19104-6297

USA

Email: manovski@econ.upenn.edu

\footnotetext{
* We have benefited from numerous discussions with our colleagues in the profession. It would be impossible to acknowledge all of them individually in this space, but we must express our deep gratitude to Andrés Erosa, Tim Kehoe, and Gustavo Ventura. We would also like to thank seminar participants at the Atlanta Fed, Calgary, California-Davis, Maryland, the Minneapolis Fed, Minnesota, Northwestern with the Chicago Fed, UPenn, Queen's, the Richmond Fed, Simon Fraser, Southern California, Tilburg, Western Ontario, Québec-Montréal, 2001 and 2002 CEA, 2002 SED, 2003 NBER Summer Institute, 2003 RESTUD Tour, 2003 CMSG, and 2004 AEA for their helpful and insightful comments.
} 


\section{Introduction}

Despite an active search for the reasons behind the large increase in wage inequality in the United States over the last 30 years, identifying the culprit has proved elusive. In this paper we suggest that the increase in the variability of productivity shocks to occupations, coupled with the endogenous response of workers to this change, can account for most of the increase in wage inequality.

Several facts, documented in detail in Section 2, characterize the changes in wage inequality in the U.S. from the early 1970s to the early 1990s.

1. Inequality of hourly wages as measured by the Gini coefficient has increased by 6.6 Gini points, or $25 \%$.

2. Over half of the increase in wage inequality was due to rising inequality within narrowly defined age-education subgroups.

3. The increase in wage inequality reflects increased dispersion in all parts of the wage distribution: real wages at the bottom of the distribution fell, and wages at the top increased.

4. Individual earnings became substantially more volatile.

We document below that there was a considerable increase in the fraction of workers switching occupations (e.g., cook, accountant, chemical engineer) over the same period. The increase is pronounced for switches defined on all one-, two-, and three-digit U.S. Census Occupational Classifications.

The link between occupational mobility and wage inequality is motivated by our finding that human capital is specific to the occupation in which an individual works. We show that occupational experience is considerably more important in determining wages than 
either industry or employer tenure. This is intuitive: one would expect the human capital loss of a truck driver who loses a job in some food industry and finds another one in the furniture industry to be lower than the loss of a truck driver who becomes a cook.

Occupational mobility and wage inequality are interrelated because occupational mobility affects the distribution of occupational tenure and, thus, of human capital. In addition, different occupations are characterized at a point in time by different levels of demand or different productivity levels. Thus, in addition to the distribution of occupational tenure in the population, wage inequality depends on the distribution of workers across occupations. To evaluate the connection between occupational mobility and wage inequality, one needs an empirically grounded general equilibrium model in which occupational mobility and wage inequality are endogenously determined.

The model we develop is based on the equilibrium search framework of Lucas and Prescott (1974) (see Alvarez and Veracierto (2000) for an important recent extension and application). In that model, agents can move between spatially separated local labor markets that the authors refer to as "islands," and, although each local market is competitive, there are frictions in moving between locations. Here we do not adopt this spatial interpretation, but think of "islands" as occupations. Further, we introduce a heterogeneity of workers with respect to their occupational experience levels and allow for occupation-specific human capital. Thus, when an individual enters an occupation, she has no occupation-specific experience. Then, given that she remains in that occupation, her level of experience increases over time. When an individual switches her occupation, she loses the experience accumulated in her previous occupation. Output and wages in each occupation are a function of the employed amount of effective labor. Occupations are subject to idiosyncratic productivity shocks. We argue that the variability of these shocks 
has increased from the early 1970s to the early 1990s.

We quantify the effects of the increased variability of the occupational productivity shocks in the following experiment. We calibrate the parameters of the model to match a number of observations for the early 1970s. Next, keeping the rest of the parameters fixed, we recalibrate the parameters governing the variability of the productivity shocks to occupations in order to match several facts on occupational mobility for the early 1990s. At no point in the calibration do we target wage inequality.

The results imply that the calibrated model accounts for over $90 \%$ of the increase in wage inequality, the decline in wage stability, and it is consistent with the other facts mentioned above. We find that, in order to match the calibration targets, the variance of productivity shocks to occupations must have increased substantially, while the persistence of the shocks must have declined. An important question is whether the endogenous increase in occupational mobility tends to increase or decrease the change in wage inequality. When only the variance of productivity shocks increases, wage inequality immediately increases if workers do not adjust their behavior. However, once workers are allowed to reallocate from less productive to more productive occupations, this endogenous response dampens the increase in inequality. When the persistence of productivity shocks declines as well, search becomes less attractive because high productivity realizations are shorterlived. Since switching occupations involves destruction of human capital, more workers choose to remain on temporarily less productive occupations. These changes in workers' behavior strongly amplify the effect of the increase in the variability of productivity shocks to occupations on wage inequality.

The assumption that occupations experience idiosyncratic productivity shocks is not controversial. The occupational mix varies substantially over time. New occupations arise 
and old ones disappear. This process depends on many factors, such as changes in technology, international trade, the demographic composition of the population, government regulations, and labor market institutions. Many occupations exhibit substantial changes in their sizes over time (see Kaboski (2000)). One of the many examples that come to mind is the experience of typesetters in the late 1970s - early 1980s. Many of these highly skilled workers had to switch occupations with the advent of computerized typesetting. Needless to say, they started in their new occupations as inexperienced, relatively low-paid workers.

A number of papers, including Bertola and Ichino (1995) and Ljungqvist and Sargent (1998), have argued that the economy became more turbulent between the 1970s and 1980s. Turbulence is typically defined as an unobservable increase in the rate of skill depreciation upon a job switch over the period. Despite the intuitive appeal of the notion of increased economic turbulence, identifying it in the data has proved difficult. We suggest that an observable increase in occupational mobility serves as a measurable manifestation of the increased turbulence. We identify the increase in turbulence with the increased variability of the occupational productivity shocks.

Most of the research on the increase in wage inequality was concentrated on explaining the rise in the college premium (e.g., Krusell, Ohanian, Ríos-Rull, and Violante (2000)). The increase in the college premium, however, accounts for about a third of the overall increase in inequality. A distinguishing feature of this paper is that it provides a theory of within-group inequality. In essence, we argue that a substantial part of the variance of wages for individuals from the same age-education group is explained by the heterogeneity of their occupational experience and by the current level of demand for the services of the occupations in which these workers choose to be employed.

The existing theories of within-group inequality mainly rely on ex-ante differences in 
workers' abilities (e.g., Caselli (1999), Lloyd-Ellis (1999), and Galor and Moav (2000)). The increase in wage inequality between the 1970s and 1990s is attributed to the increase in returns to unobserved individual abilities. This assumption implies that the increase in inequality should manifest itself in the increase in the dispersion of the persistent component of wages, a prediction at odds with the data on the increase in the transitory variance of wages. While the analysis in those articles is only qualitative, making it difficult to evaluate the quantitative importance of the increased returns to ability, the effects they describe are likely complementary to our theory. The fact that occupational mobility is observable and measurable reduces the degrees of freedom we have in accounting for the data.

The mechanism most closely related to our theory is proposed in Violante (2002). In his model, workers are randomly matched with machines that embody technologies of different vintages. Skills are vintage-specific, and the amount of skills that can be transferred to a newer machine depends on the technological distance between the vintages. He studies the effect of an increase in the productivity gap between vintages on wage inequality. Since workers receive wages proportional to the productivity of their machine, this increase in the productivity distance between machines leads to an increase in wage inequality. Wage dispersion is further increased because of the decline in skill transferability. Quantitatively, Violante's model accounts for about $30 \%$ of the rise in within-group inequality.

The paper is organized as follows. In Section 2, we document the facts motivating our analysis. We present the general equilibrium model with specific human capital and define equilibrium in Sections 3 and 4. The calibration and the quantitative experiment we perform are detailed in Section 5. The results are described in Section 6. In Section 7, we discuss the modeling choices, investigate robustness, and evaluate possible alternative explanations for the rising occupational mobility and wage inequality. Section 8 concludes. 


\section{Facts}

\subsection{Changes in the Labor Market}

From the early 1970s until the early 1990s, the labor market underwent significant changes along several dimensions - wage inequality increased, wages became more volatile, and individuals switched occupations more often. Here we document these developments.

For most of the analysis, we use data from the Panel Study of Income Dynamics (PSID), which contains annual labor market information for a panel of individuals representative of the population of the United States in each year. We choose the PSID data for two major reasons. First, it is a panel data set - a feature that we exploit in our analysis. Second, the PSID is a unique data set that permits the construction of consistent measures of occupational mobility over the 1968-1993 period and one that allows us to deal with the problem of measurement error in occupational affiliation coding that plagues the analysis of mobility in any other U.S. data set. ${ }^{1}$ We restrict the sample to male heads of household, aged 23-61, who are not self- or dual-employed and who are not working for the government. The resulting sample consists of 59,522 observations over the 1968-1993 period, with an average of 2,289 observations a year. Additional sample restrictions are imposed in some of the analysis and are discussed when relevant.

\subsubsection{Increase in Wage Inequality}

As Table 1 shows, the Gini coefficient of hourly wages for male workers has increased substantially from 0.26 in the early 1970 s to 0.33 in the early 1990 s. While some of the increase is due to the fact that the earnings premium for educated and experienced workers

\footnotetext{
${ }^{1}$ To deal with the measurement error problem, we develop a method based on the Retrospective Occupation-Industry Supplemental Data Files recently released by the PSID. This method allows us to obtain the most reliable estimates of the levels and trends in occupational mobility in the literature. We discuss this in detail in Kambourov and Manovskii (2002, 2004a,b).
} 
rose over the period, Juhn, Murphy, and Pierce (1993) estimate that over half of the increase in wage inequality was due to rising inequality within age-education groups. For example, as Figure 1 illustrates, wage inequality among college-educated workers and among high school-educated workers increased substantially during the period.

Figure 2, which is reproduced from Gottschalk (1997), reveals that the increase in wage inequality reflects changes that affected all parts of the wage distribution. The figure suggests that, between 1973 and 1994, real weekly wages have declined for almost 80\% of American men and have increased only for the top 20\%. These findings are similar to those reported in Topel (1997). ${ }^{2}$

\subsubsection{Decline in Wage Stability}

Gottschalk and Moffitt (1994) found that, during the 1980s, the short-term earnings volatility increased sharply compared to the 1970s. Formally, let $y_{i t}$ denote the log wages of individual $i$ in year $t=1,2, \ldots, T$. One can decompose $y_{i t}$ into a permanent and a transitory component in the following way:

$$
y_{i t}=\pi_{i}+\eta_{i t},
$$

where $\pi_{i}$ is the mean $\log$ wage of individual $i$ over $T$ years, while $\eta_{i t}$ is the deviation of $y_{i t}$ from the individual mean log wage in year $t$. Denote by $\operatorname{var}\left(\eta_{i}\right)$ the variance of $\eta_{i t}$ for individual $i$ over the $T$ years. Following Gottschalk and Moffitt (1994), we compute the variances of permanent and transitory components of log wages for the periods 1970-78 and 1979-87 on our sample, after first purging wages of age and education effects by regressing

\footnotetext{
${ }^{2}$ While we have data only on individual wages, a more relevant concept for our analysis is that of total compensation. Using the establishment survey data for the 1981-1997 period, Pierce (2001) finds that a changing distribution of nonwage compensation reinforces the finding of rising wage inequality. Nonwage compensation is strongly positively correlated with wages, and inequality of total compensation rose more than did wage inequality. If one incorporates workplace amenities, such as daytime versus evening/night work and injury rates, into the definition of compensation, Hamermesh (1999) suggests that the change in earnings inequality between the early 1970s and early 1990s has understated the change in inequality in returns to work measured according to this definition.
} 
them on a quartic in age and a quadratic in education. Table 1 shows that the variance of permanent log wages, $\pi_{i}$, increased $29 \%$, while the average (across individuals) variance of transitory wages, $\eta_{i t}$, increased $56 \%$ over the period. These results imply that workers faced considerably higher wage variability in the 1980s than in the 1970s. ${ }^{3}$

\subsubsection{Increase in Occupational Mobility}

As summarized in Figure 3 and Table 1, we find that occupational mobility in the U.S. has increased from $16 \%$ in the early 1970 s to $19 \%$ in the early 1990 s, at the three-digit level (see Appendices III - V for the description of the occupational codes). Occupational mobility is defined as the fraction of currently employed individuals who report a current occupation different from their most recent previous report. ${ }^{4}$ The three-digit classification defines more than 400 occupations: architect, carpenter, and mining engineer are a few examples. Figure 3 also shows that even at the one-digit level - a classification that consists of only nine broad occupational groups - there was a substantial increase in occupational mobility. Rosenfeld (1979) suggests that occupational mobility did not exhibit any trend in the 1960s.

Several additional results detailed in Kambourov and Manovskii (2004b) are relevant to this study and will motivate our modeling choices. First, occupational mobility has increased for most age-education subgroups of the population: it increased for those with a high-school diploma as well as for those with a college degree and for workers of different ages. The fact that, over the period, population composition changed in favor of relatively

\footnotetext{
${ }^{3}$ The result that short-term income volatility has increased significantly over the period is robust to various alternative assumptions in modeling the covariance structure of the earnings process in, e.g., Moffitt and Gottschalk (1995) and Heathcote, Storesletten, and Violante (2004). Blundell and Preston (1998) find a strong increase in the variance of transitory income shocks between 1968 and 1992 in British data. They use consumption data to identify transitory and permanent components of income shocks.

${ }^{4}$ For example, an individual employed in two consecutive years would be considered as switching occupations if she reports a current occupation different from the one she reported in the previous year. If an individual is employed in the current year, but was unemployed in the previous year, a switch will be recorded if current occupation is different from the one he reported when he was most recently employed.
} 
less mobile older and more educated workers masked some of the increase in mobility. The dotted line in each panel of Figure 3 illustrates that the increase in the aggregate occupational mobility would have been 2 percentage points higher if the age-education structure of the population remained constant throughout the period. Second, mobility has increased in all parts of the occupational tenure distribution. Third, the increase in occupational mobility was not driven by an increased flow of workers into or out of a particular one-digit occupation. Thus, we find no evidence of an increase in stepping-stone mobility described in Jovanovic and Nyarko (1997). Fourth, we find a very similar increase in mobility employing another commonly used measure of reallocation defined as one-half of the sum of the absolute changes in occupational employment shares. Finally, we note that occupational switches are fairly permanent: only around $20 \%$ of switchers return to their three-digit occupation within a four-year period.

We conclude that the high level of occupational mobility described here potentially implies a sizable yearly destruction of specific human capital. The increase in occupational mobility from the early 1970s to the early 1990s has significantly affected the labor market.

\subsection{Occupational Specificity of Human Capital}

In Kambourov and Manovskii (2002) we found substantial returns to tenure in a three-digit occupation - an increase in wages of at least $19 \%$ after 10 years of occupational experience. Table 2 summarizes the finding and the estimation procedure. Furthermore, we found that when experience in an occupation is taken into account, tenure within an industry or with an employer has virtually no effect on workers' wages. In other words, as long as a worker remains in the same occupation, her wages will keep growing regardless of whether she switches her industry or her employer. This finding is consistent with human capital being occupation-specific. 


\section{An Equilibrium Model with Occupation-Specific Ex- perience}

Environment. The economy consists of a continuum of occupations of measure one and ex-ante identical individuals of measure one. Individuals die (leave the labor force) each period with probability $\delta$ and are replaced by newly born ones. There are two experience levels in each occupation: workers are either inexperienced or experienced. Experience is occupation-specific, and newcomers to an occupation, regardless of the experience they had in their previous occupations, begin as inexperienced workers. Each period, an inexperienced worker in an occupation becomes experienced with probability $p$. Those who, at the beginning of the period, decide to leave their occupation, search for one period and arrive in a new occupation at the beginning of the next period. ${ }^{5}$ Search is random in the sense that the probability of arriving to a specific occupation is the same across all occupations.

Preferences. Individuals are risk-neutral and maximize:

$$
E \sum_{t=0}^{\infty} \beta^{t}(1-\delta)^{t} c_{t}
$$

where $\beta$ is the time-discount factor and $c_{t}$ denotes consumption in period $t$. The decision rules and equilibrium allocations in the model with risk-neutral workers are equivalent to those in a model with risk-averse individuals and complete insurance markets.

Production. All occupations produce the same homogeneous good. Output $y$ in an

\footnotetext{
5 The assumption that a worker switching occupations searches for one period is made in order to make the experiment we conduct in this paper more interesting and should not be interpreted as modeling unemployment. An alternative assumption would be to change the timing of the model so that the separation decisions are taken at the end of a period so that a switching worker instantaneously starts the new period in a new occupation. This would imply that we force individuals to work for one period in an occupation they may not like. Thus an increase in the variance of idiosyncratic occupation productivity shocks will necessarily increase wage inequality. We choose to allow workers to escape the low realizations of occupation productivity shocks in order to make the relationship between occupational mobility and wage inequality truly endogenous.
} 
occupation is produced with the production technology

$$
y=z\left[a g_{1}^{\rho}+(1-a) g_{2}^{\rho}\right]^{\frac{\gamma}{\rho}},
$$

where $\rho \leq 1,0<\gamma<1,0<a<1, g_{1}$ is the measure of inexperienced individuals working in the occupation, $g_{2}$ is the measure of experienced individuals working in the occupation, and $z$ denotes the idiosyncratic productivity shock. The productivity shocks evolve according to the process

$$
\ln \left(z^{\prime}\right)=\alpha+\phi \ln (z)+\epsilon^{\prime}
$$

where $0<\phi<1$ and $\epsilon^{\prime} \sim N\left(0, \sigma_{\epsilon}^{2}\right)$. We denote the transition function for $z$ as $Q\left(z, z^{\prime}\right)$.

There are a large number of competitive employers in each occupation, and the wages that the inexperienced and experienced workers receive in an occupation are equal to their respective marginal products. We assume that there are competitive spot markets for the fixed factor in each occupation, implied by the production function. The returns to the fixed factor are redistributed in a lump sum back to the workers. Since we study only the inequality of wages in this paper, without loss of generality, we do not explicitly model this redistribution.

Occupation Population Dynamics. Let $\psi=\left(\psi_{1}, \psi_{2}\right)$ denote the beginning of the period distribution of workers present in an occupation, where $\psi_{1}$ is the measure of inexperienced workers while $\psi_{2}$ is the measure of experienced ones. At the beginning of the period, the idiosyncratic productivity shock $z$ is realized. Some individuals in an occupation $(\psi, z)$ could decide to leave the occupation and search for a better one. Denote by $g(\psi, z)=$ $\left(g_{1}, g_{2}\right)$, the end of the period distribution of workers in an occupation, where $g_{j}$ is the measure of workers with experience $j=1,2$ who decide to stay and work in an occupation 
$(\psi, z) \cdot{ }^{6}$

Let $S$ be the economy-wide measure of workers searching for a new occupation. Then, $S$ and $g(\psi, z)$ determine the next period's starting distribution, $\psi^{\prime}$, of workers over experience levels in each occupation. The law of motion for $\psi$ in an occupation is

$$
\psi^{\prime}=\left(\psi_{1}^{\prime}, \psi_{2}^{\prime}\right)=\Gamma(g(\psi, z))=\left(\delta+(1-\delta) S+(1-p)(1-\delta) g_{1}, p(1-\delta) g_{1}+(1-\delta) g_{2}\right)
$$

In the beginning of the next period, the number of inexperienced workers who will start in an occupation is equal to the employed inexperienced workers this period who survive and do not advance to the next experience level, plus the newly arrived workers. Similarly, the measure of experienced workers in the beginning of the next period is equal to the employed experienced workers this period who survive, plus those employed inexperienced this period who survive and become experienced next period.

Individual Value Functions. Consider the decision problem of an individual in an occupation $(\psi, z)$ who takes as given $g(\psi, z), S$, and $V^{s}$ - the value of leaving an occupation and searching for a new one. Denote by $w_{1}(\psi, z)$ the wage of the inexperienced workers in occupation $(\psi, z)$. Then, $V_{1}(\psi, z)$, the value of starting the period in an occupation $(\psi, z)$ as an inexperienced worker, is

$$
V_{1}(\psi, z)=\max \left\{V^{s}, w_{1}(\psi, z)+\beta(1-\delta) \int\left[(1-p) V_{1}\left(\psi^{\prime}, z^{\prime}\right)+p V_{2}\left(\psi^{\prime}, z^{\prime}\right)\right] Q\left(z, d z^{\prime}\right)\right\}
$$

If the worker leaves the occupation, her expected value is equal to $V^{s}$. The value of staying and working in the occupation is equal to the wage received this period plus the expected discounted value from the next period on, taking into account the fact that with probability $p$ she will become experienced next period and with probability $\delta$ she will die.

\footnotetext{
${ }^{6}$ In general, individual decisions depend on the aggregate state of the economy as well. Since we restrict our analysis to steady states, the aggregate variables in the economy are constant. Thus, we omit them to keep the notation concise.
} 
Similarly, $V_{2}(\psi, z)$, the value of an experienced worker in an occupation $(\psi, z)$, is

$$
V_{2}(\psi, z)=\max \left\{V^{s}, w_{2}(\psi, z)+\beta(1-\delta) \int V_{2}\left(\psi^{\prime}, z^{\prime}\right) Q\left(z, d z^{\prime}\right)\right\}
$$

As in the case of inexperienced workers, if an experienced worker leaves the occupation, her expected value is equal to $V^{s}$. The value of staying and working in the occupation is equal to the wage received this period plus the expected discounted value from the next period on.

Stationary Distribution. We are focusing on a stationary environment characterized by a stationary, occupation-invariant distribution $\mu(\psi, z)$ :

$$
\mu\left(\Psi^{\prime}, Z^{\prime}\right)=\int_{\left\{(\psi, z): \psi^{\prime} \in \Psi^{\prime}\right\}} Q\left(z, Z^{\prime}\right) \mu(d \psi, d z)
$$

where $\Psi^{\prime}$ and $Z^{\prime}$ are sets of experience distributions and idiosyncratic shocks, respectively.

\section{Equilibrium}

Definition. A stationary equilibrium consists of value functions $V_{1}(\psi, z)$ and $V_{2}(\psi, z)$, occupation employment rules $g_{1}(\psi, z)$ and $g_{2}(\psi, z)$, an occupation-invariant measure $\mu(\psi, z)$, the value of search $V^{s}$, and the measure $S$ of workers switching occupations, such that:

1. $V_{1}(\psi, z)$ and $V_{2}(\psi, z)$ satisfy the Bellman equations, given $V^{s}, g(\psi, z)$, and $S$.

2. Wages in an occupation are competitively determined:

$$
\begin{gathered}
w_{1}=z \gamma a g_{1}^{\rho-1}\left[a g_{1}^{\rho}+(1-a) g_{2}^{\rho}\right]^{\frac{\gamma-\rho}{\rho}}, \\
w_{2}=z \gamma(1-a) g_{2}^{\rho-1}\left[a g_{1}^{\rho}+(1-a) g_{2}^{\rho}\right]^{\frac{\gamma-\rho}{\rho}},
\end{gathered}
$$

3. The occupation employment rule $g(\psi, z)$ is consistent with individual decisions: 
(a) If $g_{1}(\psi, z)=\psi_{1}$ and $g_{2}(\psi, z)=\psi_{2}$, then $V_{1}(\psi, z) \geq V^{s}$ and $V_{2}(\psi, z) \geq V^{s}$.

(b) If $g_{1}(\psi, z)<\psi_{1}$ and $g_{2}(\psi, z)=\psi_{2}$, then $V_{1}(\psi, z)=V^{s}$ and $V_{2}(\psi, z) \geq V^{s}$.

(c) If $g_{1}(\psi, z)=\psi_{1}$ and $g_{2}(\psi, z)<\psi_{2}$, then $V_{1}(\psi, z) \geq V^{s}$ and $V_{2}(\psi, z)=V^{s}$.

(d) If $g_{1}(\psi, z)<\psi_{1}$ and $g_{2}(\psi, z)<\psi_{2}$, then $V_{1}(\psi, z)=V^{s}$ and $V_{2}(\psi, z)=V^{s}$.

4. Individual decisions are compatible with the invariant distribution:

$$
\mu\left(\Psi^{\prime}, Z^{\prime}\right)=\int_{\left\{(\psi, z): \psi^{\prime} \in \Psi^{\prime}\right\}} Q\left(z, Z^{\prime}\right) \mu(d \psi, d z) .
$$

5. For an occupation $(\psi, z)$, the feasibility conditions are satisfied:

$$
0 \leq g_{j}(\psi, z) \leq \psi_{j} \quad \text { for } j=1,2
$$

6. Aggregate feasibility is satisfied:

$$
S=1-\int\left[g_{1}(\psi, z)+g_{2}(\psi, z)\right] \mu(d \psi, d z)
$$

7. The value of search, $V^{s}$, is generated by $V_{1}(\psi, z)$ and $\mu(\psi, z)$ :

$$
V^{s}=(1-\delta) \beta \int V_{1}(\psi, z) \mu(d \psi, d z)
$$

The algorithm for computing equilibrium in this model is presented in Appendix II.

\section{Quantitative Analysis}

\subsection{The Experiment}

The model parameters to be calibrated are:

1. $\delta$ - the probability of an individual dying,

2. $\beta$ - the time discount rate, 
3. $p$ - the probability of an inexperienced individual becoming experienced,

4. $\gamma$ - the curvature parameter of the production function,

5. $a$ - the distribution parameter of the production function,

6. $\rho$ - the substitution parameter of the production function,

7. $\alpha$ - the unconditional mean of the stochastic process generating shocks $z$,

8. $\phi$ - the persistence parameter of the stochastic process generating shocks $z$,

9. $\sigma_{\epsilon}^{2}$ - the variance of the innovations in the stochastic process generating shocks $z$.

The main experiment we perform in this paper is as follows. The first six parameters above are assumed to be invariant over the 1968-93 period. The last three parameters, $\alpha$, $\phi$, and $\sigma_{\epsilon}$, which govern the idiosyncratic occupational productivity shocks, are assumed to be different in the early 1970 s and early 1990s. Thus, we calibrate $\alpha, \phi$, and $\sigma_{\epsilon}$ to match the properties of occupational mobility separately in the 1969-72 and 1990-93 periods. At no point in the calibration do we target wage inequality.

\subsection{Calibration Details}

Most of the model parameters are directly imputed from the data. Other parameters are chosen to match observed moments, e.g., occupational mobility. We use the PSID data and maintain the sample restrictions described in Section 2.

We chose the model period to be six months since very few individuals switch occupations multiple times within a year (see Hagedorn, Kambourov, and Manovskii (2004)). Since the PSID has annual frequency, we observe only an annual rate of occupational mobility in the data. To maintain consistency between the model and the data we will pretend that we observe each individual in the model only every second period. We choose 
$\delta=0.0125$ to generate an expected working lifetime of 40 years. We set $\beta=1 /(1+r)$, where $r$ represents an annual interest rate of $4 \%$.

The probability $p$ of an inexperienced individual becoming experienced is not observable. However, an investigation of the estimated returns to occupational tenure suggests that the rate of growth of wages slows down considerably once an individual reaches roughly 10 years of occupational experience. Thus, we choose $p=0.05$, which implies that it takes, on average, 10 years for a newcomer to an occupation to become experienced in that occupation. We investigate the sensitivity of the results with respect to $p$ in Section 7.2.

Production Function. We select $\gamma=0.68$ to match the labor share implicit in the NIPA accounts. To obtain $a$ and $\rho$, we employ the following procedure. Taking the ratio of the wages paid to the experienced and inexperienced workers in an occupation, one obtains:

$$
\left(\frac{w_{2}}{w_{1}}\right)=\frac{1-a}{a}\left(\frac{g_{2}}{g_{1}}\right)^{\rho-1} .
$$

The parameters $a$ and $\rho$ can then be estimated, using the following regression model:

$$
\ln \left(\frac{w_{2}}{w_{1}}\right)_{i t}=\xi_{0}+\xi_{1} \ln \left(\frac{g_{2}}{g_{1}}\right)_{i t}+\nu_{i t},
$$

where $i$ indexes occupations, $t$ indexes time, and $\nu_{i t}$ is a classical measurement error. The parameters of interest are obtained from the following relations: $a=1 /\left(e^{\hat{\xi_{0}}}+1\right)$ and $\rho=\hat{\xi}_{1}+1$. The estimation procedure is summarized in Appendix I. The results imply that $a=0.44$ and $\rho=0.73$. We investigate the sensitivity of the results with respect to these parameters in Section 7.2.

Stochastic Process. We determine the shock values $z_{i}$ and the transition matrix $Q(z, \cdot)$ for a 15-state Markov chain $\left\{z_{1}, z_{2}, \ldots, z_{15}\right\}$ intended to approximate the postulated continuousvalued autoregression. We restrict $z_{1}$ and $z_{15}$ as implied by three unconditional standard 
deviations of $\ln (z)$ above and below the unconditional mean of the process, respectively.

We first choose $\phi$ and $\sigma_{\epsilon}$ to match the following observations for the 1969-72 period:

1. The average annual rate of occupational mobility at a three-digit level (summarized in Table 1).

2. The average number of switches for those who switched a three-digit occupation at least once over the period. This statistic is equal to 1.56 over the 1969-72 period and 1.62 over the $1990-93$ period. $^{7}$

Next, we choose $\phi$ and $\sigma_{\epsilon}$ to match the corresponding observations for the 1990-93 period. We normalize $\alpha$ to be equal to zero in the first period and adjust it in the second period to keep real average wages constant. ${ }^{8}$

Note that there is no direct analytical relation between these three parameters and the corresponding observations. We search numerically over these parameters until a good fit is found. Table 3 summarizes the values of the parameters assumed to be fixed in both periods. Table 4 contains the values of $\alpha, \phi$, and $\sigma_{\epsilon}$ that result in the best fit of the model in each period with respect to the targets specified above. As can be seen in Table 5, the model performs well in matching the calibration targets. See Table 6 for the values of the shocks and the stationary distributions of occupations over shocks in both periods.

\footnotetext{
${ }^{7}$ This statistic distinguishes if most of the occupational mobility is accounted for by a subset of workers switching occupations repeatedly or by different workers switching occasionally. Subject to the environment, it is also a measure of how directed a search is, i.e., how long, on average, it takes a worker switching occupations to find a new one that she likes. To compute the average number of occupational switches in the 1969-72 period, we restrict the sample to those who satisfy our usual sample restrictions described in Section 2 and have an occupational code in every year of the 1968-72 interval. This implies that sample size is constant in every year. The procedure used to compute this statistic in the 1990-93 period is similar.

${ }^{8}$ The choice of values of $\alpha$ in either period has no effect on the values of the statistics we are interested in in this paper. There is some controversy in the literature whether average real wages of male workers have changed in the data between the early 1970s and early 1990s. Depending on the choice of the deflator and of the exact years over which the comparison is made, some papers find them declining slightly while some others find them slightly increasing. Since this choice has no importance for our results, we pick the middle point in the range of the available estimates.
} 
The calibrated model does a good job matching other dimensions of occupational mobility that were not targeted. The fraction of individuals who do not switch a three-digit occupation throughout a four-year period in the PSID data has fallen from $63 \%$ in the early 1970 s to $50 \%$ in the early 1990 s. The corresponding statistic in the model falls from $62 \%$ to $54 \%$. Over the 1973-1993 period, the share of workers with at least 5 years of occupational experience declined $12 \%$ in the PSID data. In the model, that fraction declines $11 \%$. The decline in the share of experienced workers is consistent with the evidence in Farber (1998), who notes that the fraction of employed workers with more than 10 years of tenure with their employer declined from 0.41 in the late 1970 s to 0.35 in the mid-1990s.

\section{Results from the Calibrated Model}

Below, we describe the performance of the calibrated model in accounting for the facts documented in Section 2.1.

\subsection{Accounting for Wage Inequality and Wage Stability}

The effects of the increase in economic uncertainty on wage inequality are summarized in Table 7. The first important observation is that the model calibrated to the occupational mobility of the early 1970s generates a level of wage inequality that is over $90 \%$ of that in the data. This suggests that the model is appropriate for the study of wage inequality.

The model is also successful in accounting for the increase in wage inequality over the period. In fact, it accounts for over $90 \%$ of the increase. To look deeper at the increase in wage inequality, we use the calibrated model to construct a graph similar to the one from Gottschalk (1997) that was reproduced in Figure 2. As Figure 4 illustrates, the model does an excellent job matching the observation that the increase in wage inequality in the data reflected changes that affected all parts of the wage distribution. In particular, as in 
the data, the model predicts a decline of wages for almost $80 \%$ of the individuals and an increase only for the top $20 \%$ or so. ${ }^{9}$

With respect to wage stability, the model generates an increase in the transitory variance of wages comparable to that in the data. In computing the variance decompositions, as in Section 2, we use wages over nine consecutive years. To avoid life-cycle effects, we use individuals with 16-24 years of labor market experience. We find that the increase in the permanent variance is smaller than that in the data. Note, however, that we have assumed that individuals are ex-ante identical, a feature that makes it difficult to match the level or the increase in the permanent variance of wages in this model. ${ }^{10}$

\subsection{Fixing the Decision Rules}

The results raise an important question. Does the endogenous change in occupational mobility dampen or amplify the response of wage inequality to the changes in the shock

\footnotetext{
${ }^{9}$ The model predicts an increase in the inequality of wages among inexperienced workers of $25 \%$, and among experienced workers of $28 \%$. These changes appear similar to those in the data. The exact mapping between the model and the data in this dimension is complicated by the fact that we do not know the occupational experience of workers in the early 1970s in the PSID or any other U.S. data set. In addition, the model predicts an increase in the inequality of wages within occupations of $5 \%$ and between occupations (measured by the Gini coefficient of average wages in each occupation) of $42 \%$. A relatively small increase in within-occupation inequality is an artifact of restricting the model to only two occupational experience levels. Unfortunately, it is not possible to report the value of these statistics in the data. The PSID is too small to allow us to compute within- and between-occupations inequality (we have on average 2289 observations a year and over 400 occupations). The Current Population Survey (CPS) has a larger sample size, but has severe measurement error problems in identifying occupational affiliation and occupational earnings (see Kambourov and Manovskii (2004a)).

${ }^{10} \mathrm{An}$ interesting extension of this paper is to think of permanent heterogeneity by modeling education explicitly. We do not pursue this avenue here, since it is inessential for our argument. Briefly, as in Kambourov (2003), one can modify our model by considering two sectors with a continuum of occupations in each. One sector is populated by educated workers and the other by uneducated ones. Educated workers cannot switch occupations in their sector (it is rare that a lawyer becomes a medical doctor or a professor of physics). As in Rogerson (1999), the increase in employment in the highly productive educated occupations is accomplished by the increasing rate at which new labor market entrants enter that sector. Education is, however, substitutable with human capital generated by the experience in an occupation in the sector of uneducated workers. Thus, the workers who leave the contracting educated occupations compete for jobs with experienced uneducated workers. In such a model, an increase in the variability of productivity shocks to occupations in each sector (consistent with the data characterized by the increase in occupational mobility among educated and uneducated workers) will likely result in an increase in the education premium and an increase in the permanent variance of wages.
} 
process? To address this issue, we conduct the following experiment. After the shock process is calibrated to the observations in the early 1970s, we fix the occupation employment rules as well as the stationary distribution $\mu$ and change the shock process to the one calibrated to match the 1990s.

Performing this experiment, we find that the endogenous response of the economy (occupational mobility) to the higher degree of economic uncertainty accounts for $30 \%$ of the overall increase in wage inequality. In other words, the increase in inequality would have been $30 \%$ smaller if workers did not adjust their behavior.

In order to understand this result, it is instructive to study the changes in the distributions of employed workers across productivity shocks in the calibrated model. Figure 5 summarizes these distributions in the early 1970s and 1990s. The corresponding values of the productivity shocks are provided in Table 6 .

Figure 5 suggests that the distribution of workers over productivity shocks is shifted to the left in the 1990s relative to the corresponding distribution in the early 1970s. This implies that more workers choose to remain in the relatively unproductive occupations. Why would they do so? In the 1990s, shocks are more dispersed and are less persistent. An inexperienced worker who finds himself in a relatively unproductive occupation this period has an option of switching his occupation and searching one period for a new occupation or remaining in the current occupation and accumulating human capital. Since searching for a currently productive occupation is less attractive because of the decreased persistence of the high productivity shocks in the 1990s, more workers choose to remain on the relatively unproductive occupation. In addition, there is a higher chance of this occupation receiving a high productivity shock in the next period, and this provides additional incentives to preserve human capital. These two effects lead to an increase in the average size of the 
occupations in the middle of the distribution of productivity shocks (the shocks that have a high mass in the stationary distribution). When a low productivity shock hits one of these larger occupations, a bigger mass of workers leave it, driving the increase in occupational mobility.

Another channel that leads to an increase in wage inequality due to the endogenous response of occupational mobility is the following. The relative wages of experienced and inexperienced workers in an occupation depend on the number of workers of each type. When an occupation experiences a good productivity shock, a large number of inexperienced workers come to that occupation. This decreases wages of experienced workers but by less than wages of inexperienced ones (since $\gamma<\rho$ ). Thus, some inexperienced workers may be induced to work in a highly productive occupation, despite receiving relatively low wages, in expectation of gaining experience and receiving higher wages in the future. ${ }^{11}$

\section{Discussion and Sensitivity Analysis}

\subsection{Model Performance over a Range of Parameter Values Governing the Shock Process}

As the first step in analyzing the robustness of the findings, we study the behavior of occupational mobility and wage inequality over a large range of parameter values governing the variability of occupational productivity shocks. Panels A and B in Figure 6 present occupational mobility and the average number of switches for workers switching occupations at least once in a four-year period - the two calibration targets - for values of $\phi \in(0.05,0.99)$

\footnotetext{
${ }^{11}$ The fact that the estimates of the production function parameters entail $\rho<1$ implies that it is possible for experienced workers in an occupation to receive lower wages than the inexperienced ones do. This indeed happens occasionally in the calibrated model. However, the fraction of the population that works in the occupations where this happens is very small - less than 1\%. Eliminating such occupations from the analysis altogether leaves all of our results virtually unchanged. As part of the sensitivity analysis, we show in Section 7.2.1 that setting $\rho=1$ has a relatively small impact on our findings.
} 
and $\sigma_{\epsilon} \in(0.05,0.85)$. As these figures indicate, over these ranges, the values of both statistics rise with the increase in the standard deviation of innovations in the productivity shocks process or the increase in persistence. Panel $\mathrm{C}$ in Figure 6 describes the level of wage inequality as measured by the Gini coefficient over the parameter space. The figure implies that wage inequality is also increasing in the persistence of the shocks and the standard deviation of their innovations.

\subsection{Sensitivity of the Results with Respect to Model Parameters}

To investigate the sensitivity of our findings to the choice of the parameter values, we conduct two sets of experiments. First, we conduct a comparative statics analysis - we change one by one the values of $a, \rho$, and $p$, and, without recalibrating the model, investigate the effects such a change has on the results.

Second, we explicitly acknowledge that the probability of becoming experienced, $p$, is not directly observable in the data. Since the parameters of the production function $a$ and $\rho$ depend on $p$, i.e., on the choice of what it means to be experienced, we change these parameters jointly and recalibrate the other parameters conditional on this choice.

\subsubsection{Comparative Statics}

The results of the first set of experiments are summarized in Table 8. As discussed above, we keep all the parameters (including those governing the idiosyncratic shock process) at their calibrated values in both periods, and one by one increase (or decrease) the values of $a, \rho$, and $p$. The first insight revealed by Table 8 is that occupational mobility and wage inequality change smoothly and monotonically as we vary $a, \rho$, and $p$. Two other results in particular are worth emphasizing.

First, the analysis of the model's performance with respect to $a$ helps evaluate an 
alternative theory of the increase in wage inequality. It suggests that wage inequality might have increased because of an increase in the relative productivity of experienced workers. Suppose this is indeed what happened (say, a declined from 0.44 to 0.40 ) while the variability of occupational productivity shocks did not change over the period (it remained at its early 1970s level). Such a substantial (23 percent) increase in the relative productivity of experienced workers would indeed result in some increase in the Gini coefficient (from 0.250 to 0.265 ) and a small increase in the variance of transitory log wages (from 0.104 to 0.112). The theory, however, would have the strongly counterfactual prediction of a decline in occupational mobility from 0.155 to 0.133 . These results are similar in spirit to those in Den Haan, Haefke, and Ramey (2001) and are intuitive. If the returns to occupational experience increase, individuals respond by accumulating more human capital and switching their occupations less often.

Alternatively, one may ask what would have happened to occupational mobility and wage inequality if human capital generated by occupation-specific experience became less important over time. We evaluate this theory by increasing $a$ from 0.44 to 0.48 , implying a substantial (19 percent) decline in the relative productivity of experienced workers. As one might expect, the decline in importance of occupation-specific human capital in the model will result in an increase in occupational mobility (from 0.155 to 0.168 ). It would, however, imply a decline in wage inequality (from 0.250 to 0.236 as measured by the Gini coefficient) and the variance of transitory log wages (from 0.104 to 0.095 ) that is clearly in conflict with the data.

Second, we note the relatively small effect of choosing the substitution parameter, $\rho$, to be equal to one in the production function. In this case, experienced and inexperienced workers are perfect substitutes. As Table 8 illustrates, the same increase in the variability 
of demand shocks would result in a bigger increase in occupational mobility and a slightly smaller increase in wage inequality when $\rho=1$. This is due to the channel discussed in Section 6.2. When experienced and inexperienced workers are perfect substitutes, their relative wages are fixed. Thus, the changing relative numbers of experienced and inexperienced workers due to the changing economic environment, have no effect on their relative wages. These effects are present in our benchmark calibration.

\subsubsection{Recalibrating the Model with Different Estimates of $a, \rho$, and $p$}

In the benchmark calibration of the model, we chose $p=0.05$, which implies that it takes, on average, 10 years for a newcomer to an occupation to become experienced in that occupation. In this subsection, we investigate the sensitivity of the results with respect to $p$ ranging from 0.0625 to 0.0417 , implying that it takes either 8 or 12 years to become skilled in an occupation.

We reestimate the parameters of the production function consistent with these choices for $p$ and recalibrate the parameters of the occupational productivity shock processes in the early 1970s and 1990s. As in the benchmark calibration, in both cases it is necessary to increase the variance of the innovations in the productivity shock process and to decrease its persistence to match the increase in occupational mobility between the early 1970s and 1990s. The results from the recalibrated model are summarized in Table 9. Despite substantial changes in the implied parameter values, both recalibrated models generate increases in wage inequality similar to those in the benchmark calibration. 


\subsection{Could Declining Search Costs Have Caused the Increase in Occupational Mobility and Wage Inequality?}

It may be argued that the increase in occupational mobility was driven not by a change in the process generating idiosyncratic occupational productivity shocks but by a decline in the cost of switching occupations. We evaluate this hypothesis here. Suppose that the only change in the economic environment between the early 1970s and the 1990s was the decline in search costs. Is this consistent with the stylized facts motivating this paper?

Formally, we perform the following experiment. The model is calibrated to match the targets in the early 1970s. Then we decrease the model period from 6 months to 3 months. We recompute all the time-invariant parameters of the model to be consistent with the new model period. Since the model period is now twice shorter, we rescale the persistence of the productivity shocks $\phi^{\text {new }}=\sqrt{\phi^{\text {old }}}$ and the standard deviation of its innovations, $\sigma_{\epsilon}^{\text {new }}=\sigma_{\epsilon}^{\text {old }} / \sqrt{1+\left(\phi^{\text {new }}\right)^{2}}$. The rationale for this rescaling is that we want to keep the environment constant in the following sense. Conditional on a realization of the shock in period $t$, we keep the expected value and the expected variance of the shock in period $t+2$ identical to what they would have been in period $t+1$ with a twice longer model period.

The results of this experiment are presented in Table 10. They indicate that a substantial decline in search costs is compatible with the data on occupational mobility. The predictions about wage inequality, however, are strongly counterfactual: wage inequality as well as the permanent and transitory variances of wages decline substantially. We conclude from this experiment that if the cost of switching occupations did decrease over the period, the observed increase in wage inequality is substantially lower than what it would have been otherwise. If this is true, economists have a considerably more difficult puzzle to tackle when trying to account for the increase in wage inequality. 


\subsection{Discussion of Modeling Choices}

Random Search. We have assumed that search is random in the sense that, for a worker switching occupations, the probability of arriving at a specific occupation is the same across all occupations. An alternative is to assume that search is directed, similar to the original Lucas and Prescott (1974) model. In the directed search version of our model, there will be an equilibrium condition stating that the expected value (not wages) of starting next period in a new occupation as an inexperienced worker is equalized across occupations that are receiving workers. There is little empirical evidence to guide our choice between a random or directed search model. ${ }^{12}$ The world is probably somewhere in between. We do not require workers to work in an occupation they do not like. Thus, search in our model is directed, but it is costly (takes time) for the workers to identify productive occupations. We calibrate the model to match the observation in the data on how many times an individual switching occupations will switch within the subsequent several years.

Modeling search as being directed would yield several unsavory implications. In the data, growth rates of occupations are quite persistent, contrary to what would be implied by a perfectly directed search model. In addition, under directed search wages of inexperienced workers will be lower on highly productive occupations than on the less productive ones, where, similar to Chari and Hopenhayn (1991), workers are compensated for accumulating a less productive type of human capital. In the data, as in our model, growing occupations, on average, have higher wages for inexperienced workers than do the declining ones.

We should emphasize that all the channels we analyze in the random search model are also present in the version of the model with perfectly directed search. The level of

\footnotetext{
${ }^{12}$ In several waves of the PSID, unemployed individuals were asked to name the two-digit occupation in which they were trying to find a job. Less than $30 \%$ of these workers ended up finding a job in the desired occupation, while the large majority of them found a job in a different two-digit occupation. This casts doubt on the assumption of directed search.
} 
wage inequality may be somewhat higher or lower than in the model with random search. Similar to the model with random search, in response to the increase in the variance of the productivity shock process and to the decline in its persistence (needed to generate a higher level of mobility), there will be an increase in wage inequality in the directed search version of the model as well. The endogenous response of workers to the changing economic environment is the same in the two versions of the model.

Capital Mobility. We have assumed that while labor is perfectly mobile across occupations, capital is not. Allowing for capital mobility does not change our conclusions. Similar to Veracierto (2002) and Manovskii (2003), assume that there are a large number of competitive firms in each occupation that have access to a production technology:

$$
y=F(L, K, z)=z L^{\gamma} K^{\kappa}
$$

where $K$ represents the total amount of capital supplied to the production of output in an occupation, $L=\left[a_{1} g_{1}^{\rho}+a_{2} g_{2}^{\rho}\right]^{\frac{1}{\rho}}$, and $\gamma+\kappa \leq 1$. Capital is assumed to be perfectly mobile across occupations, and thus its rental rate, $r$, is equalized across all occupations. Thus, the amount of capital allocated to an occupation with labor supply $L$ is given by:

$$
K=\left[\frac{r}{z \kappa}\right]^{\frac{1}{\kappa-1}} L^{\frac{\gamma}{1-\kappa}}
$$

Wages for a worker with experience $i$ are then given by:

$$
w_{i}(L, z ; r)=a_{i} z^{\frac{1}{1-\kappa}} \gamma g_{i}^{\rho-1}\left[\frac{r}{\kappa}\right]^{\frac{\kappa}{\kappa-1}} L^{\frac{\gamma+\kappa \rho-\rho}{1-\kappa}}
$$

This implies that capital will reallocate toward highly productive occupations, increasing wages of the workers present in those occupations and decreasing wages on less productive occupations. Of course, in making mobility decisions, workers take capital mobility into account, and thus the idiosyncratic shock process must be recalibrated. On balance, capital 
mobility will likely tend to increase the level of wage inequality. It is unlikely, however, to affect our results about the change in occupational mobility and wage inequality between the early 1970s and early 1990s. Thus, modeling capital mobility seems inessential for any of the channels we draw attention to in this paper but makes the interpretation of the results considerably more complicated.

Gross versus Net Mobility. We have assumed that all occupational mobility decisions are driven by idiosyncratic productivity shocks to occupations. Undoubtedly, some workers switch occupations in the data for life-cycle reasons or because of some other unobserved idiosyncratic quality of the match between a worker and a particular occupation. In the PSID data, the level of gross occupational mobility that we concentrate on in this paper is about two times higher than a commonly used measure of net reallocation defined as one-half of the sum of the absolute changes in occupational employment shares. That is, if $s_{m, t}$ is the fraction of employment in occupation $m$ in year $t$, net mobility in year $t$ is given by $1 / 2 \sum_{m}\left|s_{m, t}-s_{m, t-1}\right|$. It is possible to modify the model to allow for a substantial difference between gross and net mobility. First, we can abolish the requirement that a worker switching occupations is unemployed for one period and shift the timing of the model so that all mobility decisions are taken at the end of the period and require workers to work in the occupation they arrive at. We do not do so for the reasons discussed in Footnote 5. Second, we can assume that a certain fraction of workers is exogenously thrown off the occupation they would have liked to work on and are forced to switch occupations. If this accounts for a sizable fraction of occupational mobility, we would have to recalibrate the shock process to account for the remaining part. The effect this would have on wage inequality is ambiguous, but inequality is likely to be somewhat lower. What is important, however, is that most of the increase in gross mobility that we have documented is 
accounted for by the increase in net mobility in the data. Thus, the analysis of the change in occupational mobility and wage inequality will remain unchanged.

Learning-by-Doing. We have assumed that human capital accumulation occurs through exogenous learning-by-doing. Manovskii (2003) shows that the model is easily modified to incorporate human capital accumulation that requires active investments of time in the learning process. The effect on training decisions of the change in economic environment we have described is potentially interesting and is complementary to the effects we study in this paper. There is little evidence, however, to direct our choice of modeling the human capital accumulation technology. Heckman, Lochner, and Cossa (2002) suggest that learning-by-doing is more consistent with the data, and this explains our choice.

Steady-State Analysis. We have concentrated our analysis on two stationary equilibria of the model, one referring to the early 1970s and the other to the 1990s. The main problem we face in computing transitions is that we have to take a stand on when the change in the environment occurred and if it was a one-shot change or a continuous process. We do not know the answer to this question. One could calibrate the model to match occupational mobility in every year of the transition and read the implications of the model for the path of wage inequality. This is, however, a very hard computational problem. We are comfortable restricting to the steady-state analysis because occupational mobility and wage inequality were stable in the early 1970s (Rosenfeld (1979) for the former, and Katz and Autor (1999) for the latter) and the 1990s (Kambourov and Manovskii (2004b) as well as Moscarini and Vella (2003) for the former, and Card and DiNardo (2002) for the latter) - the periods to which we calibrate our model - and the increase in both variables was concentrated in the relatively short period between the early to mid-1970s and mid-1980s. ${ }^{13}$

\footnotetext{
${ }^{13}$ As Card and DiNardo (2002) show, the fact that wage inequality stabilized in the 1990s poses a problem for the skill-biased technical change hypothesis, since computer technology continued to advance rapidly.
} 


\section{Concluding Remarks}

\subsection{Summary}

In this study, we argue that wage inequality and occupational mobility are interrelated phenomena. The link between them is motivated with our empirical findings that human capital is occupation-specific and that the fraction of workers switching occupations in the U.S. increased from $16 \%$ a year in the early 1970 s to $19 \%$ in the early 1990 s. We develop a general equilibrium model with occupation-specific human capital and heterogeneous experience of workers within occupations. The model is characterized by endogeneity of wages and occupation separation rates (i.e., endogenous destruction of occupation-specific human capital in the economy). We find that the model calibrated to match the increase in occupational mobility accounts for over $90 \%$ of the substantial increase in wage inequality over the period. Using the model, we evaluate several reasons for the increase in occupational mobility and argue that the one consistent with the data is the increase in the variability of productivity shocks to occupations. We describe the particular channels through which increased uncertainty in the economy leads to higher earnings inequality. In particular, we find that the endogenous response of workers to the changing economic environment, encapsulated in their occupational mobility decisions, accounts for $30 \%$ of the increase in wage inequality. An important friction in the market that we draw attention to is the fact that it takes time to build occupation-specific experience. A distinguishing feature of the theory is that it relies on the observable changes in occupational mobility and accounts for changes in within group wage inequality and the increase in the variability of transitory earnings. 


\subsection{Extensions}

Two major extensions of this project are worth pursuing. First, it would be interesting to obtain direct evidence on the increase in the variability of occupational productivity shocks. These shocks are not directly observable. One could infer them from wages, using a model like the one in this paper, but "in reverse." Of course, we could not use the observations on wages to back out the shock process and then use that shock process to account for wages. We would have "explained" $100 \%$ of wages by construction. One possible alternative avenue is to note that occupations are not uniformly distributed across industries. Using the industry-based stock price data, as in Loungani, Rush, and Tave (1990) and Brainard and Cutler (1993), we can attempt to infer the implied shocks to occupations. While complicated, such analysis may prove fruitful.

Second, available data imply clear differences in the wage inequality trends across countries (see Gottschalk and Smeeding (1997) for a review). It would be interesting to obtain cross-country evidence on levels and trends in occupational mobility as well. This is not a trivial task, however, since occupational classification systems and coding methodologies differ across countries. In addition, most developed countries, other than the U.S., do not have consistent occupational affiliation data going back to at least the early 1970s.

What caused the increase in variability? Answering this question is well beyond the scope of this paper. The answer is crucial, however, for our understanding of the underlying forces manifesting themselves in the rate of occupational mobility. There are several potential suspects. Consider, for example, technical change that affects the occupational mix used to produce various goods. One may, for example, recall the booming demand for web page designers just a few years ago that all but disappeared when simple web page programming software became widely available. Increase in foreign and domestic com- 
petition may have played a non-trivial role. Labor unions that span several occupations may insulate workers from fluctuating demands for the services of particular occupations. De-unionization exposes workers to those shocks. Finally, each firm employs workers from different occupations. Risk-averse workers who do not have access to perfect insurance may want firms to smooth their occupational shocks. If capital markets become more efficient over time, the demand for such insurance declines, and workers again become more exposed to occupational shocks. Distinguishing (quantitatively) between the importance of these and other mechanisms, we believe, will provide a very promising avenue for future research.

\subsection{Applications of the Theory}

Our theory potentially has a number of implications for other actively researched issues. We think that looking at numerous labor market phenomena through the prism of the occupational structure of the economy will provide new angles important for understanding the data.

Flattening Life-Cycle Wage Profiles. Beaudry and Green (2000) demonstrate that over the 1971 to 1993 period, age-earnings profiles of college- as well as high school-educated Canadian men have become flatter for the cohorts entering the labor market more recently. The U.S. data studied in Bernhardt, Morris, Handcock, and Scott (1999) exhibit similar patterns. Our theory suggests that a substantial fraction of the average life-cycle profile of wages can be explained by rising average occupational experience over the life-cycle of a cohort of workers who entered the labor market at the same time. An increase in occupational mobility results in lower average occupational experience over the cohort's life-cycle and a flatter life-cycle wage profile.

Effects of Labor Market Policies. An important insight of our theory is that any government policy that affects the occupational reallocation of labor would have an impact 
on wage inequality and labor productivity. For example, various labor income taxation or unemployment insurance schemes would have different impacts on workers' incentives for accumulating occupation-specific experience and on occupational mobility. The model we have developed in this paper is easily modified to address these issues.

The Slowdown of Productivity Growth. An intriguing research question is to relate changes in occupational mobility to changes in the growth rate of productivity. It may not be a coincidence that the increased destruction of specific human capital associated with the increase in occupational mobility we have documented has coincided with a much discussed slowdown in productivity growth. 
Table 1: Changes in the U.S. Labor Market.

\begin{tabular}{lccc}
\hline & $1969-72$ & $1990-93$ & Change \\
\hline Gini Coefficient & 0.264 & 0.330 & $25.0 \%$ \\
$\begin{array}{lccc}\text { Variance of permanent } \\
\text { log wages, var }\left(\pi_{i}\right)\end{array}$ & 0.178 & 0.230 & $29.2 \%$ \\
$\begin{array}{l}\text { Average variance of } \\
\text { transitory log wages, } \\
\text { average } \operatorname{var}\left(\eta_{i}\right)\end{array}$ & 0.110 & 0.172 & $56.4 \%$ \\
$\begin{array}{l}\text { Occupational mobility } \\
\text { Ond }\end{array}$ & 0.155 & 0.188 & $21.3 \%$ \\
\hline
\end{tabular}

Note - Authors' calculations from the PSID. For sample restrictions, see Section 2. As discussed in Section 2.1.2, the second and third lines present the decomposition of log wage (purged of education and age effects) variance into permanent and transitory components using the Gottschalk and Moffitt (1994) procedure for the 1970-78 and 1979-87 periods. Occupational mobility refers to the average annual rate of occupational mobility over the corresponding time period. See Kambourov and Manovskii (2004b) for details of the estimation procedure. 
Table 2: Occupational Specificity of Human Capital.

\begin{tabular}{|c|c|c|c|}
\hline & \multicolumn{3}{|c|}{ Returns to Experience } \\
\hline & 2 years & 5 years & 10 years \\
\hline Occupation & $\begin{array}{l}.0535 \\
(.0068)\end{array}$ & $\begin{array}{l}.1188 \\
(.0154)\end{array}$ & $\begin{array}{c}.1900 \\
(.0258)\end{array}$ \\
\hline Industry & $\begin{array}{l}-.0030 \\
(.0071)\end{array}$ & $\begin{array}{l}-.0086 \\
(.0149)\end{array}$ & $\begin{array}{l}-.0207 \\
(.0226)\end{array}$ \\
\hline Employer & $\begin{array}{c}.0012 \\
(.0096)\end{array}$ & $\begin{array}{c}.0027 \\
(.0136)\end{array}$ & $\begin{array}{c}.0079 \\
(.0212)\end{array}$ \\
\hline
\end{tabular}

Source: Kambourov and Manovskii (2002). Returns to experience represent the percentage increase in wages due to the first 2, 5, or 10 years of occupational, industry, or employer tenure. Standard errors are in parentheses. The results are computed from the estimates of the following econometric model:

$$
\begin{aligned}
\ln w_{i j m n t}= & \beta_{0} E m p_{-} T e n_{i j t}+\beta_{1} O J_{i j t}+\beta_{2} O c c_{-} T e n_{i m t}+\beta_{3} I n d_{-} T e n_{i n t} \\
& +\beta_{4} \text { Work_Exp } p_{i t}+\mu_{i}+\lambda_{i j}+\xi_{i m}+v_{i n}+\epsilon_{i t},
\end{aligned}
$$

where $w_{i j m n t}$ is the real hourly wage of person $i$ working in period $t$ with employer $j$ in occupation $m$ and industry $n$. Emp_Ten, Occ_Ten, and Ind_Ten denote tenure with the current employer, occupation, and industry, respectively. $O J$ is a dummy variable that equals one if the individual is not in the first year with the current employer. Work_Exp denotes overall labor market experience. The regression includes an individualspecific component $\mu_{i}$, a job-match component $\lambda_{i j}$, an occupation-match component $\xi_{i m}$, and an industry-match component $v_{i n}$. Other variables in the regression include an intercept term, one-digit occupation and industry dummies, a union dummy, a marital status dummy, year dummies, region dummies, education, as well as unemployment rate and lagged unemployment rate in the county of residence. The model also contains the square term of employer tenure and education, and the square and cube terms of occupation and industry tenure and overall work experience. The model is estimated using an IV-GLS procedure proposed by Altonji and Shakotko (1987). 
Table 3: Calibrated Values of Time-Invariant Parameters.

\begin{tabular}{cccccc}
\hline$\delta$ & $\gamma$ & $\beta$ & $a$ & $\rho$ & $p$ \\
\hline 0.0125 & 0.68 & 0.9804 & 0.44 & 0.73 & 0.05 \\
\hline
\end{tabular}

Table 4: Calibrated Values of Time-Dependent Parameters.

\begin{tabular}{|c|c|c|c|}
\hline & Parameter & 1969-72 & 1990-93 \\
\hline & $\phi$ & 0.934 & 0.881 \\
\hline & $\sigma_{\epsilon}$ & 0.244 & 0.375 \\
\hline & $\theta$ & 0.684 & 0.792 \\
\hline & $\alpha$ & 0.000 & -0.090 \\
\hline$\phi$ & \multirow{4}{*}{\multicolumn{3}{|c|}{$\begin{array}{l}\text { - persistence of the log shocks. } \\
\text { - standard deviation of the white noise. } \\
\text { - standard deviation of the log shocks. } \\
\text { - unconditional mean of the process. }\end{array}$}} \\
\hline$\sigma_{\epsilon}$ & & & \\
\hline$\theta$ & & & \\
\hline$\alpha$ & & & \\
\hline
\end{tabular}

Table 5: Matching the Calibration Targets.

\begin{tabular}{|c|c|c|c|c|}
\hline \multirow[t]{2}{*}{ Target } & \multicolumn{2}{|c|}{$1969-72$} & \multicolumn{2}{|c|}{$1990-93$} \\
\hline & Data & Model & Data & Model \\
\hline 1. $3 \mathrm{~d}$ occupational mobility & 0.155 & 0.155 & 0.188 & 0.188 \\
\hline $\begin{array}{l}\text { 2. The average number of } \\
\text { switches for those } \\
\text { who switched a } 3 \text {-digit } \\
\text { occupation at least once } \\
\text { in a } 4 \text {-year period }\end{array}$ & 1.56 & 1.56 & 1.62 & 1.62 \\
\hline
\end{tabular}

Note - The table describes the performance of the model in matching the targets. The data are computed by the authors from the PSID. 
Table 6: Shock Values and the Stationary Distribution of Occupations over Shocks.

\begin{tabular}{|c|c|c|c|c|}
\hline & \multicolumn{2}{|c|}{ 1969-72 } & \multicolumn{2}{|c|}{ 1990-93 } \\
\hline & $z$ & $\zeta(z)$ & $z$ & $\zeta(z)$ \\
\hline 1. & 0.128 & 0.004 & 0.085 & 0.003 \\
\hline 2. & 0.172 & 0.009 & 0.119 & 0.008 \\
\hline 3. & 0.231 & 0.021 & 0.167 & 0.019 \\
\hline 4. & 0.309 & 0.044 & 0.235 & 0.042 \\
\hline 5. & 0.415 & 0.077 & 0.330 & 0.076 \\
\hline 6. & 0.556 & 0.116 & 0.463 & 0.117 \\
\hline 7. & 0.746 & 0.149 & 0.651 & 0.152 \\
\hline 8. & 1.000 & 0.162 & 0.914 & 0.165 \\
\hline 9 & 1.341 & 0.149 & 1.284 & 0.152 \\
\hline 10. & 1.798 & 0.116 & 1.803 & 0.117 \\
\hline 11. & 2.410 & 0.077 & 2.532 & 0.076 \\
\hline 12. & 3.232 & 0.044 & 3.555 & 0.042 \\
\hline 13. & 4.333 & 0.021 & 4.993 & 0.019 \\
\hline 14. & 5.809 & 0.009 & 7.013 & 0.008 \\
\hline 15. & 7.789 & 0.004 & 9.849 & 0.003 \\
\hline $\begin{array}{l}z- \\
\zeta(z\end{array}$ & es ol & $y$ dis & $\begin{array}{l}\text { ution of } \\
\text { shocks. }\end{array}$ & \\
\hline
\end{tabular}


Table 7: Results from the Calibrated Model.

1969-72 1990-93

$\begin{array}{lll}\text { Gini coefficient } & 0.250 \quad 0.313\end{array}$

Variance of permanent $\quad 0.069 \quad 0.074$

log wages, $\operatorname{var}\left(\pi_{i}\right)$

Average variance of $\quad 0.104 \quad 0.183$

transitory log wages,

average $\operatorname{var}\left(\eta_{i}\right)$ 
Table 8: Comparative Statics.

\begin{tabular}{crrrrrr}
\hline Benchmark & $a=0.40$ & $a=0.48$ & $\rho=0.50$ & $\rho=1.00$ & $p=0.04$ & $p=0.07$ \\
$(1)$ & $(2)$ & $(3)$ & $(4)$ & $(5)$ & $(6)$ & $(7)$ \\
\hline
\end{tabular}

Occupational Mobility:

$\begin{array}{llllllll}1969-72 & 0.155 & 0.133 & 0.168 & 0.148 & 0.152 & 0.148 & 0.158 \\ 1990-93 & 0.188 & 0.160 & 0.214 & 0.178 & 0.203 & 0.187 & 0.196\end{array}$

Gini Coefficient:

$\begin{array}{llllllll}1969-72 & 0.250 & 0.265 & 0.236 & 0.262 & 0.237 & 0.254 & 0.242 \\ 1990-93 & 0.313 & 0.333 & 0.293 & 0.326 & 0.295 & 0.312 & 0.305\end{array}$

Variance of Permanent Log Wages:

$\begin{array}{llllllll}1969-72 & 0.069 & 0.083 & 0.053 & 0.077 & 0.062 & 0.072 & 0.058 \\ 1990-93 & 0.074 & 0.097 & 0.058 & 0.089 & 0.059 & 0.079 & 0.063\end{array}$

Average Variance of Transitory Log Wages:

$\begin{array}{llllllll}1969-72 & 0.104 & 0.112 & 0.095 & 0.113 & 0.093 & 0.104 & 0.101 \\ 1990-93 & 0.183 & 0.209 & 0.172 & 0.208 & 0.165 & 0.190 & 0.180\end{array}$

Note - Column (1) reports the statistics in the benchmark calibration of the model in which $a=0.44, \rho=0.73$, and $p=0.05$. The rest of the table reports how the statistics change if we keep all parameters at their benchmark-calibrated values in both periods and one by one increase or decrease the values of $a, \rho$, and $p$. 
Table 9: Recalibrating the Model with Different Estimates of $a, \rho$, and $p$.

\begin{tabular}{|c|c|c|c|c|}
\hline & \multicolumn{2}{|c|}{$a=0.41, \rho=0.85, p=0.0625$} & \multicolumn{2}{|c|}{$a=0.48, \rho=0.60, p=0.0417$} \\
\hline & $1969-72$ & 1990-93 & $1969-72$ & 1990-93 \\
\hline Gini coefficient & 0.299 & 0.340 & 0.228 & 0.286 \\
\hline $\begin{array}{l}\text { Variance of perm. } \\
\text { log wages, } \operatorname{var}\left(\pi_{i}\right)\end{array}$ & 0.072 & 0.081 & 0.064 & 0.076 \\
\hline $\begin{array}{l}\text { Average variance of } \\
\text { transitory log wages, } \\
\text { average } \operatorname{var}\left(\eta_{i}\right)\end{array}$ & 0.166 & 0.229 & 0.086 & 0.162 \\
\hline
\end{tabular}

Note - In the benchmark calibration of the model $p=0.05$, implying that it takes 10 years to become experienced in an occupation. This table reports the behavior of the model if the value of $p$ is changed. In the first case, the value of $p$ implies that it takes, on average, eight years to become experienced in an occupation. In the second case, the value of $p$ implies that one becomes experienced in an occupation after 12 years. In each of the cases, given $p$, we reestimate the values of $a$ and $\rho$ as described in Appendix I, and then recalibrate the parameters governing the occupational shock process. 
Table 10: The Effects of a Decline in the Cost of Search.

\begin{tabular}{lccc}
\hline & $\begin{array}{c}1969-72 \\
(1)\end{array}$ & $\begin{array}{c}1990-93 \\
(2)\end{array}$ & $\begin{array}{c}\text { Change (\%) } \\
(3)\end{array}$ \\
\cline { 2 - 4 } & 0.250 & 0.228 & -8.8 \\
Gini coefficient & 0.069 & 0.045 & -34.8 \\
$\begin{array}{l}\text { Variance of permanent } \\
\text { log wages }\end{array}$ & 0.103 & 0.092 & -10.7 \\
$\begin{array}{l}\text { Variance of transitory } \\
\text { log wages }\end{array}$ & & & \\
\hline & $1969-72$ & $1990-93$ & LCS Model \\
& $(1)$ & $(2)$ & $(3)$ \\
\cline { 2 - 4 } & 0.155 & 0.188 & 0.219 \\
$\begin{array}{l}\text { Occupational mobility } \\
\begin{array}{l}\text { The average number of } \\
\text { switches for those } \\
\text { who switched a 3-digit } \\
\text { occupation at least once } \\
\text { in a 4-year period }\end{array}\end{array}$ & 1.56 & 1.62 & 1.77 \\
\hline
\end{tabular}

Note - The table reports the results of an experiment in which after the model is calibrated to the performance of the economy in the 1969-72 period, the cost of search is reduced by half. Column (1) in the top panel shows statistics for the economy calibrated to the 1969-72 period. The levels of these statistics after the cost of search is reduced are described in column (2). Column (1) in the bottom panel shows the level of the targets in the 1969-72 period, while column (2) shows their level in the 1990-93 period. Column (3) describes the level of these variables after the cost of search is reduced by half in the model. 
Figure 1: The Gini Coefficient of Hourly Wages for High-School Graduates and College Graduates in the United States, 1967-1991.

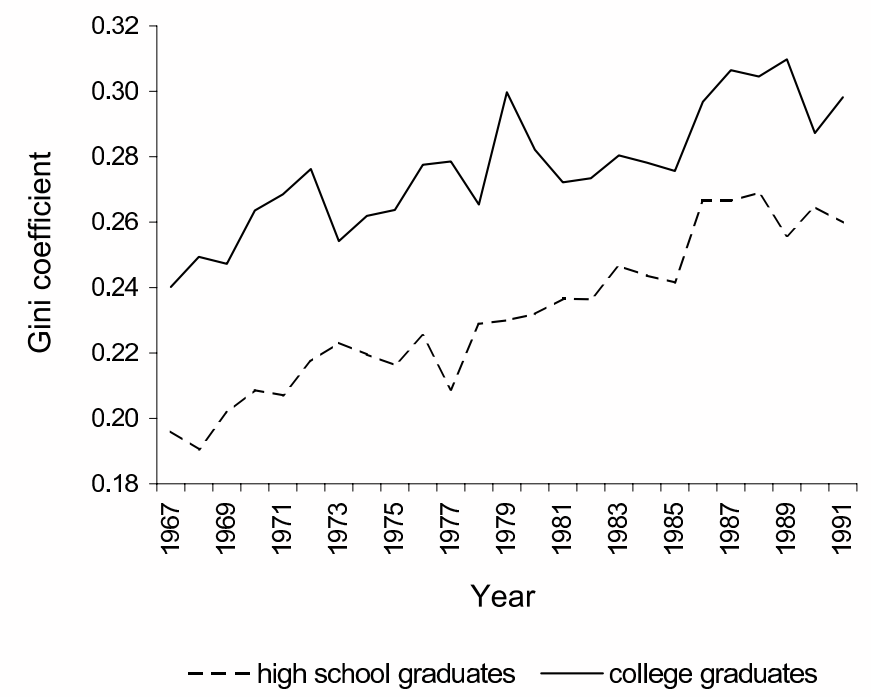

Source: Authors' calculations from the PSID.

Figure 2: Percentage Change in Real Weekly Wages by Percentiles of the Wage Distribution, 1994 vs. 1973.

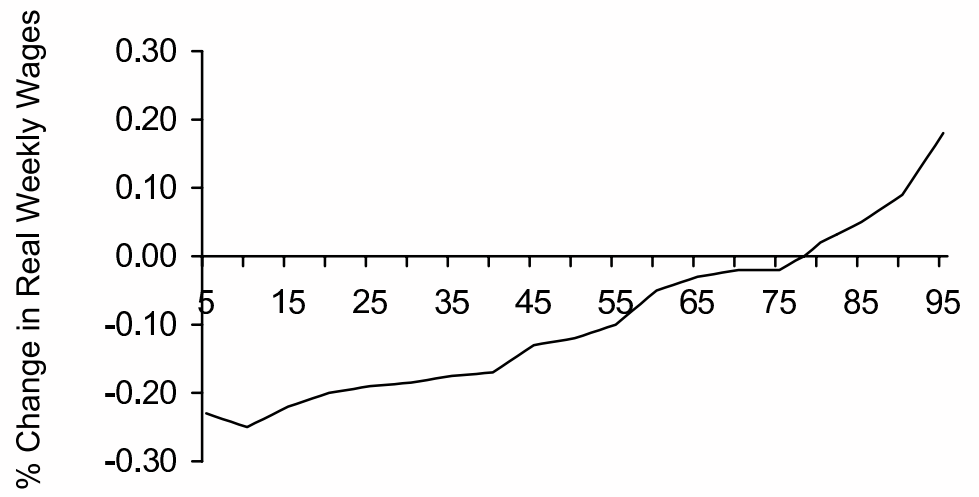

Percentile of the Wage Distribution

Source: Gottschalk (1997). 
Figure 3: Occupational Mobility in the United States, 1969-1993.

a) One digit level

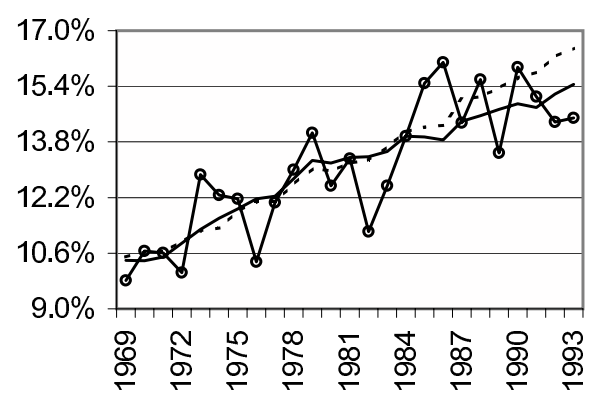

b) Two digit level

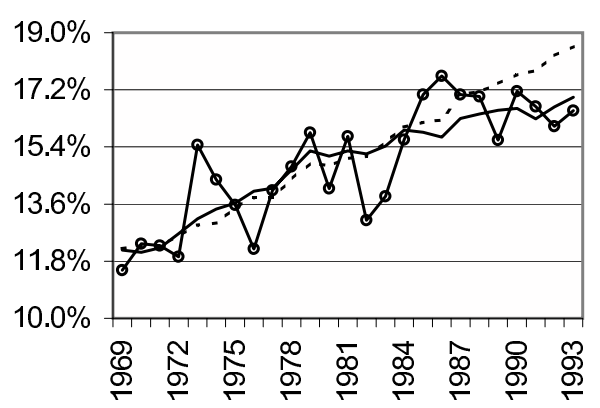

c) Three digit level
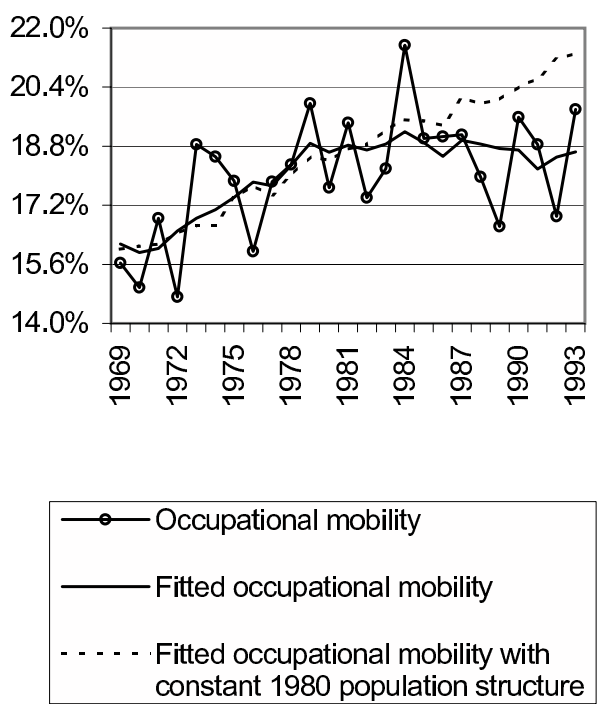

Source: Kambourov and Manovskii (2004b). 
Figure 4: Percentage Change in Real Weekly Wages by Percentiles of the Wage Distribution, Computed from the Calibrated Model.

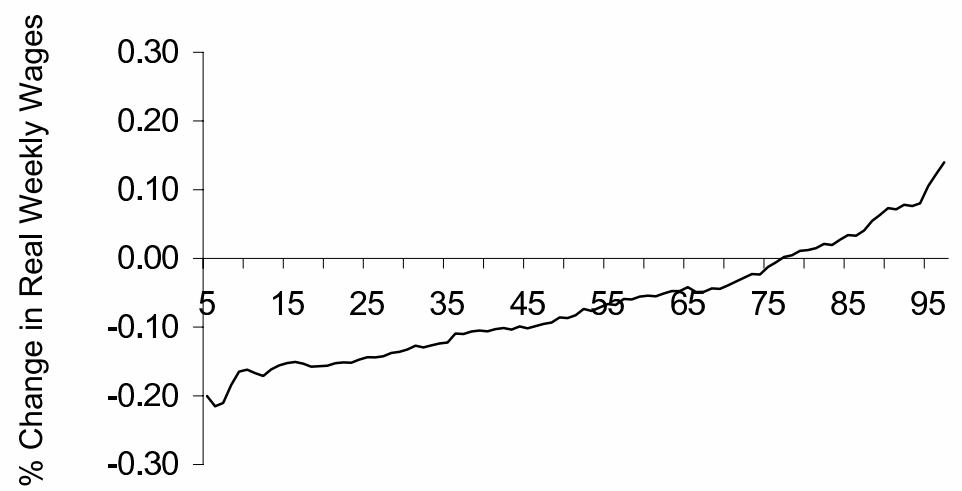

Percentile of the Wage Distribution 
Figure 5: Distribution of Workers over Productivity Shocks in the Calibrated Model, early 1970s vs. 1990s.

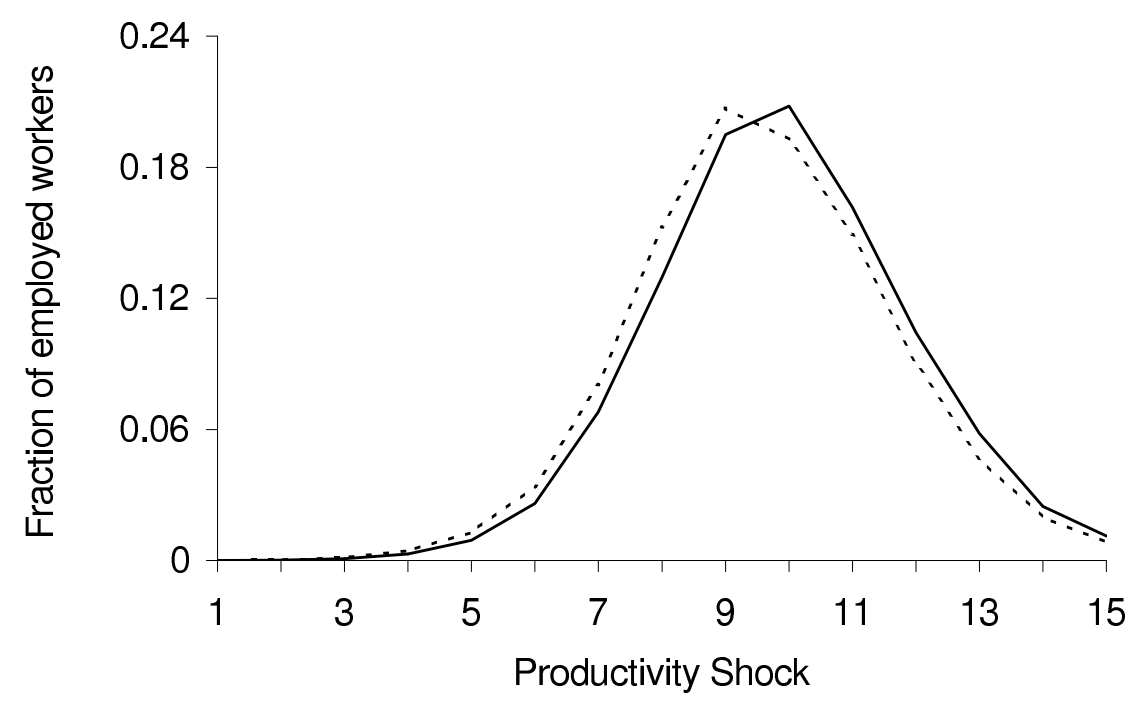

early 1970s

early 1990s 
Figure 6: The Effect of the Standard Deviation and Persistence of the Occupation Productivity Shocks.
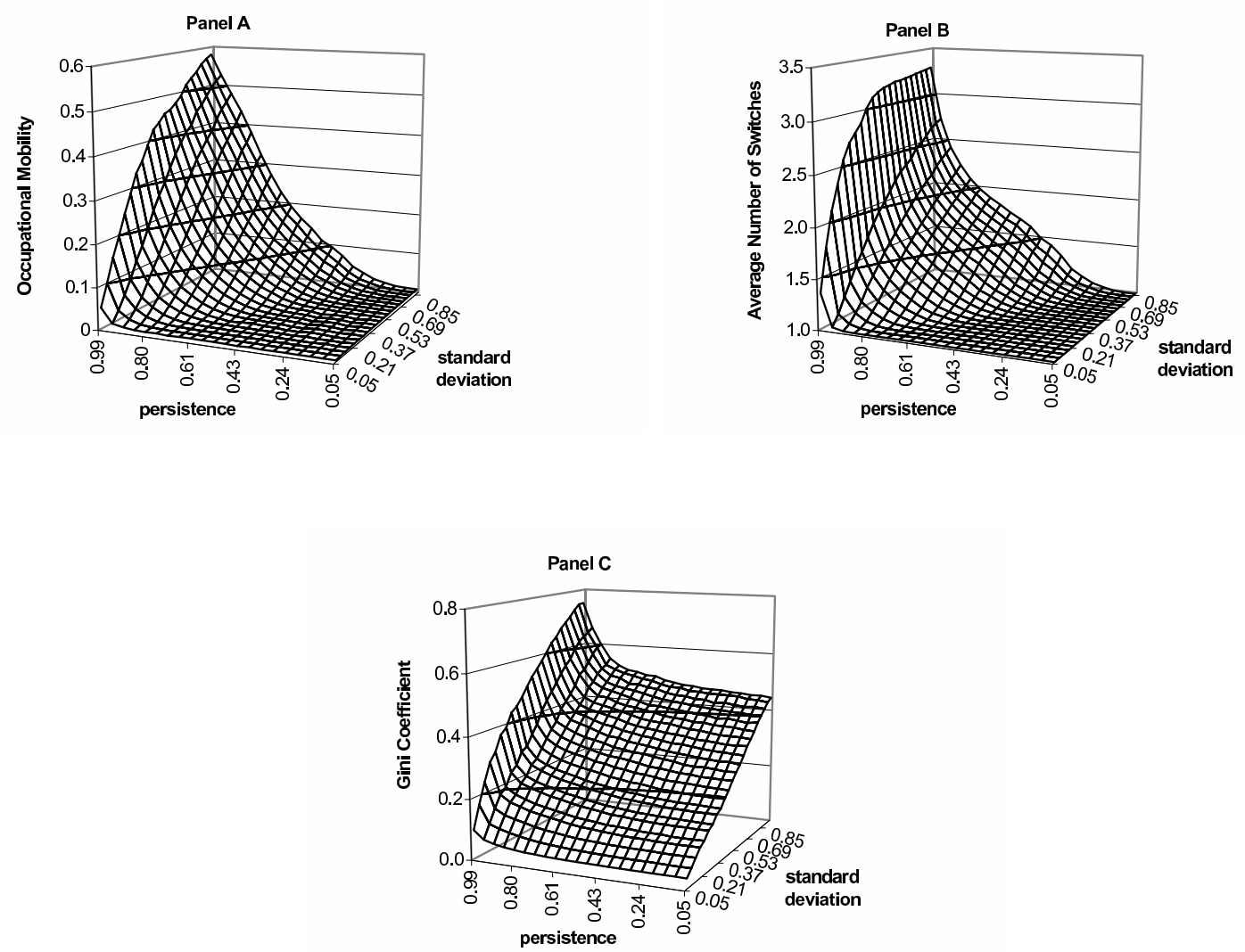

Note - Panel A shows the behavior of occupational mobility in the model as a function of the persistence $(\phi)$ and standard deviation $\left(\sigma_{\epsilon}\right)$ of the occupation productivity shocks. Similarly, Panel B shows the behavior of the average number of switches for those who have switched their occupation at least once in a 4-year period. Finally, Panel C shows the effect of the standard deviation and persistence of the occupation productivity shocks on the Gini coefficient of wages. 


\section{References}

Altonji, J., and R. Shakotko (1987): "Do Wages Rise with Job Seniority," Review of Economic Studies, 54, 437-459.

Alvarez, F., And M. Veracierto (2000): "Equilibrium Search and Labor Market Policies: a Theoretical Analysis," mimeo, University of Chicago.

Beaudry, P., And D. A. Green (2000): "Cohort Patterns in Canadian Earnings: Assessing the Role of Skill Premia in Inequality Trends," Canadian Journal of Economics, $33(4), 907-936$.

Bernhardt, A., M. Morris, M. Handcock, And M. Scott (1999): "Inequality and Mobility: Trends in Wage Growth for Young Adults," Working Paper 99-03, Population Research Institute, The Pennsylvania State University.

Bertola, G., And A. IChino (1995): "Wage Inequality and Unemployment: United States vs. Europe," in NBER Macroeconomics Annual, ed. by B. Bernanke, and J. Rotemberg. The MIT Press.

Blundell, R., And I. Preston (1998): "Consumption Inequality and Income Uncertainty," Quarterly Journal of Economics, 113(2), 603-640.

Brainard, S. L., And D. M. Cutler (1993): "Sectoral Shifts and Cyclical Unemployment Reconsidered," Quarterly Journal of Economics, 108(1), 219-243.

Card, D., And J. E. DiNardo (2002): "Skill-Biased Technological Change and Rising Wage Inequality: Some Problems and Puzzles," Journal of Labor Economics, 20(4), $733-783$. 
Caselli, F. (1999): "Technological Revolutions," American Economic Review, 89(1), 78 102.

Chari, V., and H. Hopenhayn (1991): "Vintage Human Capital, Growth, and the Diffusion of New Technology," Journal of Political Economy, 99(6), 1142-1165.

Den Haan, W., C. Haefke, and G. Ramey (2001): "Shocks and Institutions in a Job Matching Model," NBER Working Paper W8493.

FArber, H. S. (1998): "Mobility and Stability: The Dynamics of Job Change in Labor Markets," Working Paper 400, Princeton University, Industrial Relations Section.

Galor, O., And O. Moav (2000): “Ability-Based Technological Transition, Wage Inequality, and Economic Growth," Quarterly Journal of Economics, 115(2), 469-497.

Gottschalk, P. (1997): "Inequality, Income Growth, and Mobility: The Basic Facts," Journal of Economic Perspectives, 11(2), 21-40.

Gottschalk, P., And R. Moffitt (1994): "The Growth of Earnings Instability in the U.S. Labor Market," Brookings Papers on Economic Activity, 2, 217-272.

Gottschalk, P., And T. M. Smeeding (1997): "Cross-National Comparisons of Earnings and Income Inequality," Journal of Economic Literature, 35, 633-687.

Hagedorn, M., G. Kambourov, and I. Manovskit (2004): "Worker Mobility in the United States and Germany: a Primer," mimeo, University of Pennsylvania.

Hamermesh, D. S. (1999): "Changing Inequality in Markets for Workplace Amenities," Quarterly Journal of Economics, 114(4), 1085-1123. 
Heathcote, J., K. Storesletten, and G. L. Violante (2004): "The Cross-Sectional Implications of Rising Wage Inequality in the United States," mimeo, New York University.

Heckman, J. J., L. Lochner, and R. Cossa (2002): "Learning-By-Doing Vs. On-theJob Training: Using Variation Induced by the EITC to Distinguish Between Models of Skill Formation," NBER Working Paper W9083.

Jovanovic, B., And Y. Nyarko (1997): "Stepping Stone Mobility," Carnegie-Rochester Conference Series on Public Policy, 46(1), 289-326.

Juhn, C., K. Murphy, and B. Pierce (1993): "Wage Inequality and the Rise in Returns to Skill," Journal of Political Economy, 101, 410-42.

Kaboski, J. P. (2000): "Growth, Technology and Inequality with Rising Educational Attainment," mimeo, University of Chicago.

Kambourov, G. (2003): "Firing Costs and the Sectoral Reallocation of Workers: The Case of Trade Liberalizations," mimeo, University of Toronto.

Kambourov, G., and I. Manovskit (2002): "Occupational Specificity of Human Capital," mimeo, The University of Western Ontario.

- (2004a): "A Cautionary Note on Using (March) CPS Data to Study Worker Mobility," mimeo, The University of Pennsylvania.

- (2004b): "Rising Occupational and Industry Mobility in the United States: 19681993," PIER Working Paper No. 04-012; IZA Discussion Paper No. 1110. 
Katz, L. F., And D. H. Autor (1999): "Changes in Wage Structure and Earnings Inequality," in Handbook of Labor Economics, ed. by O. Ashtenfelter, and D. Card, vol. 3A, pp. 1463-1555. Amsterdam: North Holland.

Krusell, P., L. E. Ohanian, J.-V. Ríos-Rull, and G. L. Violante (2000): "Capital-Skill Complementarity and Inequality: A Macroeconomic Analysis," Econometrica, 68, 1029-1053.

Ljungqvist, L., And T. J. SARgent (1998): "The European Unemployment Dilemma," Journal of Political Economy, 106(3), 514-550.

Lloyd-Ellis, H. (1999): "Endogenous Technological Change and Wage Inequality," American Economic Review, 89(1), 47-77.

Loungani, P., M. Rush, and W. Tave (1990): "Stock Market Dispersion, Unemployment, and GNP," Journal of Monetary Economics, 25(3), 367-388.

Lucas, R. J., And E. Prescott (1974): "Equilibrium Search and Unemployment," Journal of Economic Theory, 7, 188-209.

ManovskiI, I. (2003): "Productivity Gains from Progressive Taxation of Labor Income," mimeo, University of Pennsylvania.

Moffitt, R., and P. Gottschalk (1995): "Trends in Covariance Structure of Earnings in the U.S.: 1969-1987," mimeo, Boston College.

Moscarini, G., And F. Vella (2003): "Aggregate Worker Reallocation and Occupational Mobility in the United States: 1976-2000," mimeo, Yale University. 
Pierce, B. (2001): “Compensation Inequality," Quarterly Journal of Economics, 116(4), $1493-1525$.

Rogerson, R. (1999): "Sectoral Shocks, Human Capital, and Displaced Workers," Working Paper, University of Pennsylvania.

Rosenfeld, C. (1979): "Occupational Mobility During 1977," Monthly Labor Review, 102(12), 44-48.

Topel, R. H. (1997): "Factor Proportions and Relative Wages: The Supply-Side Determinants of Wage Inequality," Journal of Economic Perspectives, 11(2), 55-74.

Veracierto, M. (2002): "On the Cyclical Behavior of Employment, Unemployment and Labor Force Participation," Working Paper 2002-12, Federal Reserve Bank of Chicago.

Violante, G. L. (2002): "Technological Acceleration, Skill Transferability and the Rise in Residual Inequality," Quarterly Journal of Economics, 117(1), 297-338. 


\section{APPENDICES}

\section{Estimating the Production Function Parameters}

In this appendix, we discuss the estimation procedure for $a$ and $\rho$. We postulate the following regression model:

$$
\ln \left(\frac{w_{2}}{w_{1}}\right)_{i t}=\xi_{0}+\xi_{1} \ln \left(\frac{g_{2}}{g_{1}}\right)_{i t}+\nu_{i t}
$$

where $i$ indexes occupations and $t$ indexes time. Further, $w_{1}$ and $w_{2}$ denote the wages that inexperienced and experienced workers receive in occupation $i$ in period $t$, while $g_{1}$ and $g_{2}$ denote the number of inexperienced and experienced workers.

The way individuals are classified into inexperienced and experienced in an occupation is conditional on our choice of the parameter $p$ - the probability of an inexperienced worker becoming experienced. Given $p$, it takes, on average, $x=\frac{1}{p}$ periods for an individual to become experienced in an occupation. For instance in the benchmark case, $p=0.05$ implying that $x$ is 20 periods (or 10 years since the model period is six months). Therefore, in the benchmark case, we considered workers to be experienced if their occupational tenure is over 10 years. In the cases when we consider a different value for the parameter $p$, we also change the value of $x$ accordingly and our interpretation of inexperienced and experienced workers. The same cut-off point is used for all occupations.

We construct workers' tenure in an occupation in the following way. We allow individuals into the sample after they either switch an occupation for the first time or accumulate more than $\frac{x}{2}$ years of occupational experience. ${ }^{14}$ Upon an occupational switch, a worker's

\footnotetext{
${ }^{14}$ It is not possible to determine the exact occupation tenure of individuals who appear for the first time in the sample, for individuals who occasionally drop out from the survey, or for individuals who change their head-of-household status in some years. These are followed until they switch their occupation or until they accumulate enough tenure in the current one to ensure that they could be considered experienced, and only then they are included in the experiments.
} 
occupational tenure is set to zero. From then on, if a worker is employed in the current year, does not switch her occupation, and reports to have worked more than 1000 hours during the previous year, her occupational tenure is increased by 12 months. If she reports to be unemployed this year or reports less than 1000 hours worked in the previous year, her occupation tenure remains unchanged. ${ }^{15}$ The switches are identified using the Retrospective Files during 1968-1980 and the originally coded data after 1980. Following Kambourov and Manovskii (2002), on the original data we consider an occupation switch to be a genuine one if there is a corresponding position or employer switch. If an individual reports a new occupation but does not indicate a position or an employer change, no occupation switch is considered to have occurred.

To eliminate the effect on wages of variables that are not explicitly modeled we first run an OLS regression of wages on overall labor market experience (a linear, quadratic, and cubic term), education (a linear and quadratic term), region of residence, marital status, union status, year, and current and last year's level of unemployment in the county of residence. The effect of these variables is subtracted from observed wages.

Finally, given our partition of the sample into experienced and inexperienced workers in each occupation, we compute $\left(w_{2} / w_{1}\right)_{i t}$ and $\left(g_{2} / g_{1}\right)_{i t}$, for each occupation $i$ in every year $t$. We consider only occupations that have at least five experienced as well as five inexperienced individuals in a given year.

The regression model A1 is then estimated using ordinary least squares.

\footnotetext{
${ }^{15}$ The results are robust to our choice of 1000 hours cut-off.
} 


\section{Computational Algorithm}

1. Guess $S$ and $V^{s}$.

2. Define a grid of points on $\left(\psi_{1}, \psi_{2}, z\right)$.

3. Guess a function $V_{1}^{0}\left(\psi_{1}, \psi_{2}, z\right)$ that is (weakly) decreasing and (weakly) convex in $\psi_{1}$, a function $V_{2}^{0}\left(\psi_{1}, \psi_{2}, z\right)$ that is (weakly) decreasing and (weakly) convex in $\psi_{2}$, and a function $H^{0}\left(\psi_{1}, \psi_{2}, z\right)$ that is (weakly) increasing in $\psi_{1}$ and $\psi_{2}$.

4. For each point on the $\left(\psi_{1}, \psi_{2}, z\right)$ grid, find the optimal policies $g_{1}$ and $g_{2}$ in the following way. Set $G=\left(\psi_{1}, \psi_{2}\right)$. Then,

(a) If both $V_{1}\left(\psi_{1}, \psi_{2}, z\right) \geq V^{s}$ and $V_{2}\left(\psi_{1}, \psi_{2}, z\right) \geq V^{s}$, everybody present in the occupation will choose to stay and thus $g_{1}=\psi_{1}$ and $g_{2}=\psi_{2}$ is a consistent policy. Go to 5 .

(b) If the condition in (a) is not satisfied, then

i. Set $G=\left(\overline{g_{1}}, \psi_{2}\right)$, where $\overline{g_{1}}$ solves the following equation:

$$
\begin{aligned}
& z \gamma a{\overline{g_{1}}}^{\rho-1}\left[a{\overline{g_{1}}}^{\rho}+(1-a) \psi_{2}^{\rho}\right]^{\frac{\gamma-\rho}{\rho}}+ \\
& \beta(1-p) \sum_{z^{\prime}} V_{1}\left(\delta+(1-\delta)\left(S+(1-p) \overline{g_{1}}\right),(1-\delta)\left(p \overline{g_{1}}+\psi_{2}\right), z^{\prime}\right) Q\left(z, z^{\prime}\right)+ \\
& \beta p \sum_{z^{\prime}} V_{2}\left(\delta+(1-\delta)\left(S+(1-p) \overline{g_{1}}\right),(1-\delta)\left(p \overline{g_{1}}+\psi_{2}\right), z^{\prime}\right) Q\left(z, z^{\prime}\right)=V^{s} .
\end{aligned}
$$

Check whether under this policy $V_{2}\left(\psi_{1}, \psi_{2}, z\right) \geq V^{s}$ and whether $\overline{g_{1}}$ is feasible. If not, then this $G$ cannot be a consistent policy. If yes, then $G$ is a candidate for the optimal policy.

ii. Set $G=\left(\psi_{1}, \overline{g_{2}}\right)$, where $\overline{g_{2}}$ solves the following equation:

$$
z \gamma(1-a){\overline{g_{2}}}^{\rho-1}\left[a \psi_{1}^{\rho}+(1-a){\overline{g_{2}}}^{\rho}\right]^{\frac{\gamma-\rho}{\rho}}+
$$




$$
\beta \sum_{z^{\prime}} V_{2}\left(\delta+(1-\delta)\left(S+(1-p) \psi_{1}\right),(1-\delta)\left(p \psi_{1}+\bar{g}_{2}\right), z^{\prime}\right) Q\left(z, z^{\prime}\right)=V^{s}
$$

Check whether under this policy $V_{1}\left(\psi_{1}, \psi_{2}, z\right) \geq V^{s}$ and whether $\overline{g_{2}}$ is feasible. If not, then this $G$ cannot be a consistent policy. If yes, then $G$ is a candidate for the optimal policy.

iii. Set $G=\left(\overline{g_{1}}, \overline{g_{2}}\right)$ where $\overline{g_{1}}$ and $\overline{g_{2}}$ jointly solve the equations in $i$ and $i i$ above. Check whether $\overline{g_{1}}$ and $\overline{g_{2}}$ are feasible. If not, then this $G$ cannot be a consistent policy. If yes, then $G$ is a candidate for the optimal policy.

iv. The optimal policy is a candidate policy from the previous three cases that maximizes the value function $H\left(\psi_{1}, \psi_{2}, z\right)^{16}$, where

$$
H(\psi, z)=\max \left\{z\left[a g_{1}^{\rho}+(1-a) g_{2}^{\rho}\right]^{\gamma / \rho}+\beta \sum_{z^{\prime}} H\left(\psi^{\prime}, z^{\prime}\right) Q\left(z, z^{\prime}\right)\right\}
$$

5. Given the optimal policy $G=\left(g_{1}, g_{2}\right)$ obtained above, update the value functions and get $V_{1}^{1}\left(\psi_{1}, \psi_{2}, z\right), V_{2}^{1}\left(\psi_{1}, \psi_{2}, z\right)$, and $H^{1}\left(\psi_{1}, \psi_{2}, z\right)$.

6. Use $V_{1}, V_{2}$, and $H$ obtained above as the new guess in step 3 .

7. Repeat steps 4 through 6 until the policy and value functions converge.

8. Simulate a large number of occupations until the distribution of occupations generates an invariant $V^{s}$ and $S$, scaling the economy at each iteration to have measure one of individuals.

9. Compare the obtained $V^{s}$ and $S$ with the initial guess in 1 . If they are the same, stop. If not, make a new guess in 1 that is a convex combination of the previous guess and the simulated values.

\footnotetext{
${ }^{16}$ This procedure chooses the equilibrium that maximizes the expected present discounted value of production in an occupation or, alternatively, total wages and the returns to the (unobserved) fixed factor.
} 


\section{Three-Digit Occupational Codes}

PROFESSIONAL, TECHNICAL, AND KINDRED WORKERS ${ }^{17}$

001 Accountants

002 Architects

Computer specialists

003 Computer programmers

004 Computer systems analysts

005 Computer specialists, not elsewhere classified

Engineers

006 Aeronautical and astronautical engineers

010 Chemical engineers

011 Civil engineers

012 Electrical and electronic engineers

013 Industrial engineers

014 Mechanical engineers

015 Metallurgical and materials engineers

020 Mining engineers

021 Petroleum engineers

022 Sales engineers

023 Engineers, not elsewhere classified

024 Farm management advisors

025 Foresters and conservationists

026 Home management advisors

Lawyers and judges

030 Judges

031 Lawyers

Librarians, archivists, and curators

032 Librarians

033 Archivists and curators

Mathematical specialists

034 Actuaries

035 Mathematicians

036 Statisticians

Life and physical scientists

042 Agricultural scientists

043 Atmospheric and space scientists

044 Biological scientists

045 Chemists

051 Geologists

\footnotetext{
${ }^{17}$ Source: PSID wave XIV - 1981 documentation, Appendix 2: Industry and Occupation Codes.
}

052 Marine scientists

053 Physicists and astronomers

054 Life and physical scientists, not elsewhere classified

055 Operations and systems researchers and analysts 056 Personnel and labor relations workers

Physicians, dentists, and related practitioners

061 Chiropractors

062 Dentists

063 Optometrists

064 Pharmacists

065 Physicians, medical and osteopathic

071 Podiatrists

072 Veterinarians

073 Health practitioners, not elsewhere classified

Nurses, dietitians, and therapists

074 Dietitians

075 Registered nurses

076 Therapists

Health technologists and technicians

080 Clinical laboratory technologists and technicians

081 Dental hygienists

082 Health record technologists and technicians

083 Radiologic technologists and technicians

084 Therapy assistants

085 Health technologists and technicians,

not elsewhere classified

Religious workers

086 Clergymen

090 Religious workers, not elsewhere classified

Social scientists

091 Economists

092 Political scientists

093 Psychologists

094 Sociologists

095 Urban and regional planners

096 Social scientists, not elsewhere classified

Social and recreation workers

100 Social workers

101 Recreation workers

Teachers, college and university

102 Agriculture teachers

103 Atmospheric, earth, marine, and space teachers

104 Biology teachers

105 Chemistry teachers 
110 Physics teachers

111 Engineering teachers

112 Mathematics teachers

113 Health specialties teachers

114 Psychology teachers

115 Business and commerce teachers

116 Economics teachers

120 History teachers

121 Sociology teachers

122 Social science teachers, not elsewhere classified

123 Art, drama, and music teachers

124 Coaches and physical education teachers

125 Education teachers

126 English teachers

130 Foreign language teachers

131 Home economics teachers

132 Law teachers

133 Theology teachers

134 Trade, industrial, and technical teachers

135 Miscellaneous teachers, college and university

140 Teachers, college and university, subject not specified

Teachers, except college and university

141 Adult education teachers

142 Elementary school teachers

143 Prekindergarten and kindergarten teachers

144 Secondary school teachers

145 Teachers, except college and university, not elsewhere classified

Engineering and science technicians

150 Agriculture and biological technicians, except health

151 Chemical technicians

152 Draftsmen

153 Electrical and electronic engineering technicians

154 Industrial engineering technicians

155 Mechanical engineering technicians

156 Mathematical technicians

161 Surveyors

162 Engineering and science technicians, not elsewhere classified

Technicians, except health, and engineering and science

163 Airplane pilots

164 Air traffic controllers

165 Embalmers

170 Flight engineers

171 Radio operators

172 Tool programmers, numerical control

173 Technicians, not elsewhere classified

174 Vocational and educational counselors

Writers, artists, and entertainers

175 Actors

180 Athletes and kindred workers
181 Authors

182 Dancers

183 Designers

184 Editors and reporters

185 Musicians and composers

190 Painters and sculptors

191 Photographers

192 Public relations men and publicity writers

193 Radio and television announcers

194 Writers, artists, and entertainers, not elsewhere classified

195 Research workers, not specified

\section{MANAGERS AND ADMINISTRATORS, EXCEPT FARM}

201 Assessors, controllers, and treasurers; local public administration

202 Bank officers and financial managers

203 Buyers and shippers, farm products

205 Buyers, wholesale and retail trade

210 Credit men

211 Funeral directors

212 Health administrators

213 Construction inspectors, public administration

215 Inspectors, except construction, public administration

216 Managers and superintendents, building

220 Office managers, not elsewhere classified

221 Officers, pilots, and pursers; ship

222 Officials and administrators; public administration, not elsewhere classified

223 Officials of lodges, societies, and unions

224 Postmasters and mail superintendents

225 Purchasing agents and buyers, not elsewhere classified

226 Railroad conductors

230 Restaurant, cafeteria, and bar managers

231 Sales managers and department heads, retail trade

233 Sales managers, except retail trade

235 School administrators, college

240 School administrators, elementary and secondary

245 Managers and administrators, not elsewhere classified

\section{SALES WORKERS}

260 Advertising agents and salesmen

261 Auctioneers

262 Demonstrators

264 Hucksters and peddlers

265 Insurance agents, brokers, and underwriters

266 Newsboys

270 Real estate agents and brokers

271 Stock and bond salesmen

280 Salesmen and sales clerks, not elsewhere classified 
Salesmen were divided into 5 categories dependent on industry. The industry codes are shown in parentheses.

281 Sales representatives, manufacturing industries (Ind. 107-399)

282 Sales representatives, wholesale trade

(Ind. 017-058, 507-599)

283 Sales clerks, retail trade

(Ind. 608-699 except 618, 639, 649, 667, $668,688)$

284 Salesmen, retail trade (Ind. 607, 618, 639, 649, 667, 668, 688)

285 Salesmen of services and construction

(Ind. 067-078, 407-499, 707-947)

\section{CLERICAL AND KINDRED WORKERS}

301 Bank tellers

303 Billing clerks

305 Bookkeepers

310 Cashiers

311 Clerical assistants, social welfare

312 Clerical supervisors, not elsewhere classified

313 Collectors, bill and account

314 Counter clerks, except food

315 Dispatchers and starters, vehicle

320 Enumerators and interviewers

321 Estimators and investigators, not elsewhere classified

323 Expediters and production controllers

325 File clerks

326 Insurance adjusters, examiners, and investigators

330 Library attendants and assistants

331 Mail carriers, post office

332 Mail handlers, except post office

333 Messengers and office boys

334 Meter readers, utilities

Office machine operators

341 Bookkeeping and billing machine operators

342 Calculating machine operators

343 Computer and peripheral equipment operators

344 Duplicating machine operators

345 Key punch operators

350 Tabulating machine operators

355 Office machine operators, not elsewhere classified

360 Payroll and timekeeping clerks

361 Postal clerks

362 Proofreaders

363 Real estate appraisers

364 Receptionists

Secretaries

370 Secretaries, legal

371 Secretaries, medical

372 Secretaries, not elsewhere classified

374 Shipping and receiving clerks
375 Statistical clerks

376 Stenographers

381 Stock clerks and storekeepers

382 Teacher aides, except school monitors

383 Telegraph messengers

384 Telegraph operators

385 Telephone operators

390 Ticket, station, and express agents

391 Typists

392 Weighers

394 Miscellaneous clerical workers

395 Not specified clerical workers

CRAFTSMEN AND KINDRED WORKERS

401 Automobile accessories installers

402 Bakers

403 Blacksmiths

404 Boilermakers

405 Bookbinders

410 Brickmasons and stonemasons

411 Brickmasons and stonemasons, apprentices

412 Bulldozer operators

413 Cabinetmakers

415 Carpenters

416 Carpenter apprentices

420 Carpet installers

421 Cement and concrete finishers

422 Compositors and typesetters

423 Printing trades apprentices, except pressmen

424 Cranemen, derrickmen, and hoistmen

425 Decorators and window dressers

426 Dental laboratory technicians

430 Electricians

431 Electrician apprentices

433 Electric power linemen and cablemen

434 Electrotypers and stereotypers

435 Engravers, except photoengravers

436 Excavating, grading, and road machine operators, except bulldozer

440 Floor layers, except tile setters

441 Foremen, not elsewhere classified

442 Forgemen and hammermen

443 Furniture and wood finishers

444 Furriers

445 Glaziers

446 Heat treaters, annealers, and temperers

450 Inspectors, scalers, and graders; log and lumber

452 Inspectors, not elsewhere classified

453 Jewelers and watchmakers

$454 \mathrm{Job}$ and die setters, metal

455 Locomotive engineers

456 Locomotive firemen

461 Machinists

462 Machinist apprentices

Mechanics and repairmen

470 Air conditioning, heating, and refrigeration 
471 Aircraft

472 Automobile body repairmen

473 Automobile mechanics

474 Automobile mechanic apprentices

475 Data processing machine repairmen

480 Farm implement

481 Heavy equipment mechanics, including diesel

482 Household appliance and accessory installers and mechanics

483 Loom fixers

484 Office machine

485 Radio and television

486 Railroad and car shop

491 Mechanic, except auto, apprentices

492 Miscellaneous mechanics and repairmen

495 Not specified mechanics and repairmen

501 Millers; grain, flour, and feed

502 Millwrights

503 Molders, metal

504 Molder apprentices

505 Motion picture protectionists

506 Opticians, and lens grinders and polishers

510 Painters, construction and maintenance

511 Painter apprentices

512 Paperhangers

514 Pattern and model makers, except paper

515 Photoengravers and lithographers

516 Piano and organ tuners and repairmen

520 Plasterers

521 Plasterer apprentices

522 Plumbers and pipe fitters

523 Plumber and pipe fitter apprentices

525 Power station operators

530 Pressmen and plate printers, printing

531 Pressman apprentices

533 Rollers and finishers, metal

534 Roofers and slaters

535 Sheetmetal workers and tinsmiths

536 Sheetmetal apprentices

540 Shipfitters

542 Shoe repairmen

543 Sign painters and letterers

545 Stationary engineers

546 Stone cutters and stone carvers

550 Structural metal craftsmen

551 Tailors

552 Telephone installers and repairmen

554 Telephone linemen and splicers

560 Tile setters

561 Tool and die makers

562 Tool and die maker apprentices

563 Upholsterers

571 Specified craft apprentices, not elsewhere classified

572 Not specified apprentices

575 Craftsmen and kindred workers, not elsewhere classified

\section{ARMED FORCES}

600 Members of armed forces

\section{OPERATIVES, EXCEPT TRANSPORT}

601 Asbestos and insulation workers

602 Assemblers

603 Blasters and powdermen

604 Bottling and canning operatives

605 Chainmen, rodmen, and axmen; surveying

610 Checkers, examiners, and inspectors; manufacturing

611 Clothing ironers and pressers

612 Cutting operatives, not elsewhere classified

613 Dressmakers and seamstresses, except factory

614 Drillers, earth

615 Dry wall installers and lathers

620 Dyers

621 Filers, polishers, sanders, and buffers

622 Furnacemen, smeltermen, and pourers

623 Garage workers and gas station attendants

624 Graders and sorters, manufacturing

625 Produce graders and packers, except factory and farm

626 Heaters, metal

630 Laundry and dry cleaning operatives, not elsewhere classified

631 Meat cutters and butchers, except manufacturing

633 Meat cutters and butchers, manufacturing

634 Meat wrappers, retail trade

635 Metal platers

636 Milliners

640 Mine operatives, not elsewhere classified

641 Mixing operatives

642 Oilers and greasers, except auto

643 Packers and wrappers,except meat and produce 644 Painters, manufactured articles

645 Photographic process workers

Precision machine operatives

650 Drill press operatives

651 Grinding machine operatives

652 Lathe and milling machine operatives

653 Precision machine operatives, not elsewhere classified

656 Punch and stamping press operatives

660 Riveters and fasteners

661 Sailors and deckhands

662 Sawyers

663 Sewers and stitchers

664 Shoemaking machine operatives

665 Solderers

666 Stationary firemen

Textile operatives

670 Carding, lapping, and combing operatives

671 Knitters, loopers, and toppers

672 Spinners, twisters, and winders 


\section{Weavers}

674 Textile operatives, not elsewhere classified

680 Welders and flame-cutters

681 Winding operatives, not elsewhere classified

690 Machine operatives, miscellaneous specified

692 Machine operatives, not specified

694 Miscellaneous operatives

695 Not specified operatives

\section{TRANSPORT EQUIPMENT OPERATIVES}

701 Boatmen and canalmen

703 Bus drivers

704 Conductors and motormen, urban rail transit

705 Deliverymen and routemen

706 Fork lift and tow motor operatives

710 Motormen; mine, factory, logging camp, etc.

711 Parking attendants

712 Railroad brakemen

713 Railroad switchmen

714 Taxicab drivers and chauffeurs

715 Truck drivers

\section{LABORERS, EXCEPT FARM}

740 Animal caretakers, except farm

750 Carpenters' helpers

751 Construction laborers, except carpenters' helpers

752 Fishermen and oysterman

753 Freight and material handlers

754 Garbage collectors

755 Gardeners and groundskeepers, except farm

760 Longshoremen and stevedores

761 Lumbermen, raftsmen, and woodchoppers

762 Stock handlers

763 Teamsters

764 Vehicle washers and equipment cleaners

770 Warehousemen, not elsewhere classified

780 Miscellaneous laborers

785 Not specified laborers

FARMERS AND FARM MANAGERS

801 Farmers (owners and tenants)

802 Farm managers

\section{FARM LABORERS AND FARM FOREMEN}

821 Farm foremen

822 Farm laborers, wage workers

823 Farm laborers, unpaid family workers

824 Farm service laborers, self-employed

\section{SERVICE WORKERS, EXCEPT PRIVATE HOUSEHOLD}

Cleaning service workers

901 Chambermaids and maids, except private

household

902 Cleaners and charwomen

903 Janitors and sextons
Food service workers

910 Bartenders

911 Busboys

912 Cooks, except private household

913 Dishwashers

914 Food counter and fountain workers

915 Waiters

916 Food service workers, not elsewhere classified, except private household

Health service workers

921 Dental assistants

922 Health aides, except nursing

923 Health trainees

924 Lay midwives

925 Nursing aides, orderlies, and attendants

926 Practical nurses

Personal service workers

931 Airline stewardesses

932 Attendants, recreation and amusement

933 Attendants, personal service, not elsewhere classified

934 Baggage porters and bellhops

935 Barbers

940 Boarding and lodging house keepers

941 Bootblacks

942 Child care workers, except private household

943 Elevator operators

944 Hairdressers and cosmetologists

945 Personal service apprentices

950 Housekeepers, except private household

952 School monitors

953 Ushers, recreation and amusement

954 Welfare service aides

Protective service workers

960 Crossing guards and bridge tenders

961 Firemen, fire protection

962 Guards and watchmen

963 Marshals and constables

964 Policemen and detectives

965 Sheriffs and bailiffs

PRIVATE HOUSEHOLD WORKERS

980 Child care workers, private household

981 Cooks, private household

982 Housekeepers, private household

983 Laundresses, private household

984 Maids and servants, private household 


\section{Two-Digit Occupational Codes}

PROFESSIONAL, TECHNICAL AND KINDRED WORKERS (001-195) ${ }^{18}$

10. Physicians (medical + osteopathic), Dentists $(062,065)$

11. Other Medical and Paramedical: chiropractors, optometrists, pharmacists, veterinarians, nurses, therapists, healers, dieticians (except medical and dental technicians, see 16) (061,063,064,071-076)

12. Accountants and Auditors (001)

13. Teachers, Primary and Secondary Schools (including NA type) (141-145)

14. Teachers, College; Social Scientists; Librarians; Archivists (032-036,091-096,102-140)

15. Architects; Chemists; Engineers; Physical and Biological Scientists (002,006-023,042-054)

16. Technicians: Airplane pilots and navigators, designers, draftsmen, foresters and conservationists, embalmers, photographers, radio operators, surveyors, technicians (medical, dental, testing, n.e.c.) (003-005,025,055,080-085,150-173,183,191)

17. Public Advisors: Clergymen, editors and reporters, farm and home management advisors, personnel and labor relations workers, public relations persons, publicity workers, religious, social and welfare workers $(024,026,056,086,090,100-101,184,192)$

18. Judges; Lawyers $(030,031)$

19. Professional, technical and kindred workers not listed above $(174,175-182,185,190,193-195)$

\section{MANAGERS, OFFICIALS AND PROPRIETORS (EXCEPT FARM) (201-245)}

20. Not self-employed

31. Self-employed (unincorporated businesses)

\section{CLERICAL AND KINDRED WORKERS}

40. Secretaries, stenographers, typists $(370-372,376,391)$

41. Other Clerical Workers: agents (n.e.c.) library assistants and attendants, bank tellers, cashiers, bill collectors, ticket, station and express agents, etc., receptionists (301-364,374-375,381-390, 392-395)

\section{SALES WORKERS}

45. Retail store salesmen and sales clerks, newsboys, hucksters, peddlers, traveling salesmen, advertising agents and sales- men, insurance agents, brokers, and salesmen, etc. (260-285)

\footnotetext{
${ }^{18}$ Numbers in parentheses represent the 3 -digit codes from the 1970 Census of Population.
}

CRAFTSMEN, FOREMEN, AND KINDRED WORKERS

50. Foremen, n.e.c. (441)

51. Other craftsmen and kindred workers (401-440,442-580)

52. Government protective service workers: firemen, police, marshals, and constables (960-965)

OPERATIVES AND KINDRED WORKERS

61. Transport equipment operatives (701-715)

62. Operatives, except transport (601-695)

\section{LABORERS}

70. Unskilled laborers-nonfarm (740-785)

71. Farm laborers and foremen (821-824)

\section{SERVICE WORKERS}

73. Private household workers (980-984)

75. Other service workers: barbers, beauticians, manicurists, bartenders, boarding and lodging housekeepers, counter and fountain workers, housekeepers and stewards, waiters, cooks, midwives, practical nurses, babysitters, attendants in physicians' and dentists' offices (901-965 except 960-965 when work for local, state, or federal government)

\section{FARMERS AND FARM MANAGERS}

80. Farmers (owners and tenants) and managers (except code 71) (801-802)

\section{MISCELLANEOUS GROUPS}

55. Members of armed forces

99. NA; DK

00. Inap.; No to C42; unemployed; retired, permanently disabled, housewife, student; $\mathrm{V} 7706=3-8 ; \mathrm{V} 7744=5$ or 9 


\section{One-Digit Occupational Codes}

01. Professional, technical, and kindred workers $(10-19)^{19}$

02. Managers, officials, and proprietors (20)

03. Self-employed businessmen (31)

04. Clerical and sales workers (40-45)

05. Craftsmen, foremen, and kindred workers (50-52)

06. Operatives and kindred workers (61-62)

07. Laborers and service workers, farm laborers (70-75)

08. Farmers and farm managers (80)

09. Miscellaneous (armed services, protective workers) (55)

\footnotetext{
${ }^{19}$ Numbers in parentheses represent 2-digit occupation codes, recoded by the authors based on PSID documentation.
} 